\title{
TESTING OF SEASONAL FRACTIONAL INTEGRATION IN UK AND JAPANESE CONSUMPTION AND INCOME
}

\author{
by \\ L A Gil-Alaña \\ Humboldt University, Berlin, and University of Navarre, Spain \\ and \\ P M Robinson \\ London School of Economics and Political Science
}

$\underline{\text { Contents: }}$

Abstract

1. Introduction and summary

2. Tests for seasonal integration

3. Empirical applications

4. The UK case

5. The Japanese case

6. Concluding remarks

Appendix

References

Tables 1 - 10

Discussion paper

No. EM/00/402

November 2000
The Suntory Centre

Suntory and Toyota International Centres for Economics and Related Disciplines

London School of Economics and Political Science

Houghton Street

London WC2A 2AE

Tel.: 020-7405 7686

Research supported by ESRC Grant R000235892. The second author's research was also supported by a Leverhulme Trust Personal Research Professorship. 


\begin{abstract}
The seasonal structure of quarterly UK and Japanese consumption and income is examined by means of fractionally-based tests proposed by Robinson (1994). These series were analysed from an autoregressive unit root viewpoint by Hylleberg, Engle, Granger and Yoo (HEGY, 1990) and Hylleberg, Engle, Granger and Lee (HEGL, 1993). We find that seasonal fractional integration, with amplitudes possibly varying across frequencies, is an alternative plausible way of modelling these series.
\end{abstract}

Keywords: Fractional integration; nonstationarity; seasonality.

JEL No.: C22

(C) by the authors. All rights reserved. Short sections of text, not to exceed two paragraphs, may be quoted without explicit permission, provided that full credit, including (C) notice, is given to the source. 


\section{Introduction and summary}

Many macroeconomic time series contain important seasonal components. A simple model for a time series $y_{t}$ is a regression on dummy variables $S_{i t}$

$$
y_{t}=m_{0}+\sum_{i=1}^{s-1} m_{i} S_{i t}+\varepsilon_{t}, \quad \varepsilon_{t} \sim \text { iid },
$$

where $s$ is the number of time periods in a year and the $m_{i}$ are unknown coefficients. Stochastic processes have also been widely used in modelling seasonality, for example, the stationary seasonal ARMA

$$
\Phi_{p}\left(L^{s}\right) y_{t}=\Theta_{q}\left(L^{s}\right) \varepsilon_{t}, \quad \varepsilon_{t} \sim \text { iid }
$$

where $\Phi_{p}\left(L^{s}\right)$ and $\Theta_{q}\left(L^{s}\right)$ are polynomials in $L^{s}$ (the seasonal lag operator) of orders $p$ and $q$ respectively, with the zeros of $\Phi_{p}\left(L^{s}\right)$ outside the unit circle and the zeros of $\Theta_{q}\left(L^{s}\right)$ outside or on the unit circle. As an alternative to (1) and (2), it may be appropriate to allow for stochastic seasonal stationarity, as is implicit in the practice of seasonal differencing (see eg. Box and Jenkins, 1970) whereby the operator $\left(1-\mathrm{L}^{\mathrm{s}}\right)$ produces a stationary weakly dependent sequence. For example, for quarterly data, $\rho\left(L^{s}\right)=\left(1-L^{4}\right)$ can be factored as $(1-L)(1+L)(1+$ $\mathrm{L}^{2}$ ), containing four zeros of modulus unity; one at zero frequency; one at two cycles per year, corresponding to frequency $\pi$; and two complex pairs at one cycle per year, corresponding to frequencies $\pi / 2$ and $3 \pi / 2$ (of a cycle $2 \pi$ ).

A good deal of empirical work has followed this approach: Hylleberg, Engle, Granger and Yoo (1990) (henceforth HEGY) found evidence for seasonal unit roots in quarterly U.K. nondurable consumption and disposable income, using a procedure that allows tests for unit roots at some seasonal frequencies without maintaining their presence at all such frequencies. Beaulieu and Miron (1993) extended the HEGY procedure to monthly data and examined twelve macroeconomic series in monthly and quarterly data. By contrast with previous studies, they concluded that evidence in favour of a seasonal unit root was weak. These findings have been seriously questioned by Hylleberg, Jorgesen and Sorensen (1993), who concluded that seasonality is in many cases variable, not fixed. Hylleberg, Engle, Granger and Lee (1993) (henceforth 
HEGL) performed the HEGY test on quarterly series of Japanese real consumption and real disposable income, suggesting that income is integrated of order $1(\mathrm{I}(1))$ at 0 and at all seasonal frequencies, $\pi / 2, \pi$ and $3 \pi / 2$, and consumption is $\mathrm{I}(1)$ at frequencies 0 and $\pi$, while some difficulty was found in separating unit roots at frequency $\pi / 2$ (and $3 \pi / 2$ ) from a deterministic seasonal pattern. Osborn (1993) suggested that a nonstationary periodic AR(1) or a periodically integrated I(1) processes could be more useful.

Seasonal unit roots can be viewed not only in an autoregressive framework but also as a particular case of seasonal fractionally integrated processes. Consider the process

$$
\left(1-L^{s}\right)^{d} y_{t}=u_{t} \text {, }
$$

where $d>0$ and $u_{t}$ is an $I(0)$ series, which is defined here as a covariance stationary process with spectral density bounded and bounded away from zero at all frequencies. Clearly, $\mathrm{y}_{\mathrm{t}}$ has s roots of modulus unity, all with the same integration order d. (3) can be extended to present different integration orders for each seasonal frequency, whereas $y_{t}$ is stationary if all orders are smaller than $1 / 2$. We say that $y_{t}$ has seasonal long memory at a given frequency if the integration order at that frequency is greater than zero.

Few empirical studies have been carried out in relation to seasonal fractional models. The notion of fractional Gaussian noise with seasonality was suggested by Jonas (1981) and extended in a Bayesian framework by Carlin, Dempster and Jonas (1985) and Carlin and Dempster (1989). Porter-Hudak (1990) applied a seasonal fractionally integrated model to quarterly U.S. monetary aggregate with the conclusion that a fractional ARMA model could be more appropriate than standard ARIMAs. Advantages of seasonal fractionally differencing models for forecasting monthly data are illustrated in Sutcliffe (1994), and another empirical application is found in Ray (1993).

In the following section we briefly describe some common tests for seasonal integration, and compare them with Robinson's (1994) tests for nonstationary hypotheses which permit testing of seasonal fractional integration of any stationary or nonstationary degree. Section 3 describes models to be tested, using Robinson's (1994) approach, to macroeconomic data 
of United Kingdom (Section 4) and Japan (Section 5) analyzed in HEGY (1990) and HEGL (1993) respectively. Section 6 contains some concluding remarks.

\section{Tests for seasonal integration}

We first consider the Dickey, Hasza and Fuller (DHF) (1984) test of $\rho_{s}=$ 1 in

$$
\left(1-\rho_{s} L^{s}\right) y_{t}=\varepsilon_{t}, \quad \varepsilon_{t} \sim \operatorname{iid}\left(0, \sigma^{2}\right)
$$

The test is based on the auxiliary regression

$$
\left(1-L^{s}\right) y_{t}=\pi y_{t-s}+\varepsilon_{t},
$$

the test statistic being the t-ratio corresponding to $\pi$ in (4). Due to the nonstandard asymptotic distributional properties of the t-ratios under the null hypothesis, DHF (1984) provide simulated critical values for testing against the alternative $\pi<0$. In order to whiten the errors in (4), the auxiliary regression may be augmented by lagged $\left(1-L^{s}\right) y_{t^{\prime}}$ and with deterministic components, but unfortunately this changes the distribution of the test statistic. A limitation in DHF (1984) is that it jointly tests for roots at zero and seasonal frequencies, and therefore does not allow for unit roots at some but not all seasonal frequencies.

This defect is overcome by HEGY (1990) for the quarterly case. Their test is based on the auxiliary regression

$$
\left(1-L^{4}\right) y_{t}=\pi_{1} y_{1 t-1}+\pi_{2} y_{2 t-1}+\pi_{3} y_{3 t-2}+\pi_{4} y_{3 t-1}+\varepsilon_{t},
$$

where $y_{1 t}=\left(1+L+L^{2}+L^{3}\right) y_{t}$ removes the seasonal unit roots but leaves in the zero frequency unit root, $y_{2 t}=-\left(1-L+L^{2}-L^{3}\right) y_{t}$ leaves the root at $\pi$ and $y_{3 t}=-(1-$ $\left.L^{2}\right) y_{t}$ leaves the roots at $\pi / 2$ and $3 \pi / 2$. The existence of unit roots at $0, \pi, \pi / 2$ (and $3 \pi / 2$ ) implies that $\pi_{1}=0, \pi_{2}=0$, and $\pi_{3}=\pi_{4}=0$ respectively. The t-ratio for $\pi_{1}$ and $\pi_{2}$ is shown by HEGY to have the familiar Dickey-Fuller distribution (see Fuller, 1976) under the null of $\pi_{1}=0$ and $\pi_{2}=0$ respectively, while the $\mathrm{t}$ ratio for $\pi_{3}$, conditional on $\pi_{4}=0$ has the distribution described by DHF (1984) for $\mathrm{s}=2$. Also a joint test of $\pi_{3}=\pi_{4}=0$ is proposed based on the F-ratio, and the critical values of the distribution tabulated. A crucial fact in these tests is that 
the same limit distributions are obtained when it is not known a priori that some of the $\pi^{\prime}$ s are zero: if the $\pi^{\prime}$ s other than the one to be tested are truly nonzero, then the process does not have unit roots at these frequencies and the corresponding $y^{\prime} s$ are stationary. If however some of the other $\pi^{\prime}$ s are zero, there are other unit roots in the regression, but the corresponding $y^{\prime}$ s are now asymptotically uncorrelated and the null distribution of the test statistic will not be affected by the inclusion of a variable with a zero coefficient which is orthogonal to the included variables. An extension of this procedure to allow joint HEGY-type tests for the presence of unit roots at zero and all seasonal frequencies, and only for the seasonal frequencies, is given in Ghysels et al. (1994). It is shown that the test statistics will have the same limiting distribution as the sum of the corresponding squared t-ratios for $\pi_{i}(i=1,2,3,4)$ in the former, and $\pi_{\mathrm{i}}(\mathrm{i}=2,3,4)$ in the latter test.

All these procedures test for a unit root in the seasonal AR operator and have stochastic nonstationarity as the null hypothesis. Canova and Hansen (1995) seasonally extend the test of Kwiatkowski et al. (1992), and propose a Lagrange multiplier test (the $\mathrm{CH}$ test) based on the residuals from a regression extracting the seasonal and other deterministic components, for testing the null of stationarity about a deterministic seasonal pattern. Hylleberg (1995) compares small sample properties of HEGY and $\mathrm{CH}$ tests for seasonal unit roots in quarterly series, concluding that both tests complement each other. More recently, Tam and Reinsel (1997) propose a test for a unit root in the seasonal MA operator, testing a deterministic seasonal null against a stochastic nonstationary alternative. They consider the (integrated) SMA(1) model,

$$
\begin{gathered}
y_{t}=\mu_{t}+u_{t}, \quad t=1-s, \ldots, 0, \\
\left(1-L^{s}\right) y_{t}=\left(1-\alpha L^{s}\right) u_{t}, \quad t=1,2, \ldots,
\end{gathered}
$$

where $\mu_{t}$ is a deterministic seasonal mean, so that $\mu_{t}-\mu_{t-s}=0$, and $u_{t}$ is initially, a white noise process. Thus, a test of $\alpha=1$ in (7) can be interpreted as a test of deterministic seasonality against the alternative $\alpha<1$ of stochastic integrated seasonality. 
The tests described above consider the possibility of only a single form of seasonal stochastic nonstationary, in particular, unit roots. We now describe the tests of Robinson (1994), which can test any integer or fractional root of any order on the unit circle in the complex plane.

We observe $\left\{\left(y_{t}, z_{t}\right), t=1,2, \ldots n\right\}$ where

$$
\begin{aligned}
y_{t}=\beta^{\prime} z_{t}+x_{t}, & t=1,2 \ldots, \\
\rho(L ; \theta) x_{t}=u_{t}, & t=1,2, \ldots, \\
x_{t}=0, & t \leq 0,
\end{aligned}
$$

where $\beta$ is a $(k x 1)$ vector of unknown parameters and $z_{t}$ is a $(k x 1)$ vector of deterministic variables that might include an intercept, a time trend and/or seasonal dummies; $\rho(L ; \theta)$, a prescribed function of $L$ and the unknown (px1) parameter vector $\theta$, will depend on the model tested; $u_{t}$ is an $I(0)$ process with parametric spectral density

$$
f(\lambda ; \tau)=\frac{\sigma^{2}}{2 \pi} g(\lambda ; \tau), \quad-\pi<\lambda \leq \pi,
$$

where the positive scalar $\sigma^{2}$ and the (qx1) vector $\tau$ are unknown, but $g$ is of known form. In general we wish to test the null hypothesis

$$
H_{o}: \theta=0 \text {. }
$$

Under (11), the residuals are $\hat{u}_{t}=\rho(L) y_{t}-\hat{\beta}^{\prime} w_{t}, \mathrm{t}=1,2, \ldots$, where

$$
\rho(L)=\rho(L ; 0) ; \quad \hat{\beta}=\left(\sum_{t=1}^{n} w_{t} w_{t}{ }^{\prime}\right)^{-1} \sum_{t=1}^{n} w_{t} \rho(L) y_{t} ; \quad w_{t}=\rho(L) z_{t} .
$$

Unless $\mathrm{g}$ is completely known function (eg. $\mathrm{g} \equiv 1$, as when $\mathrm{u}_{\mathrm{t}}$ is white noise) we have to estimate the nuisance parameter vector $\tau$, for example by $\hat{\tau}=\arg \min _{\tau \in \mathrm{T}} \sigma^{2}(\tau)$, where $\mathrm{T}$ is a suitable subset of $\mathrm{R}^{\mathrm{q}}$ and

$$
\sigma^{2}(\tau)=\frac{2 \pi}{n} \sum_{j=1}^{n-1} g\left(\lambda_{j} ; \tau\right)^{-1} I\left(\lambda_{j}\right) ; \quad I\left(\lambda_{j}\right)=\left|\frac{1}{\sqrt{2 \pi n}} \sum_{t=1}^{n} \hat{u}_{t} e^{i \lambda_{j} t}\right|^{2} ; \quad \lambda_{j}=\frac{2 \pi j}{n} .
$$

The test statistic, derived from the Lagrange multiplier (LM) principle, is

$$
\hat{R}=\frac{n}{\hat{\sigma}^{4}} \hat{a}^{\prime} \hat{A}^{-1} \hat{a}=\hat{r}^{\prime} \hat{r}
$$


where $\hat{r}=\frac{n^{1 / 2}}{\hat{\sigma}^{2}} \hat{A}^{-1 / 2} \hat{a} ; \quad \hat{\sigma}^{2}=\sigma^{2}(\hat{\tau}) ; \quad \hat{a}=\frac{-2 \pi}{n} \sum_{j}^{*} \psi\left(\lambda_{j}\right) g\left(\lambda_{j} ; \hat{\tau}\right)^{-1} I\left(\lambda_{j}\right)$,

$$
\begin{gathered}
\hat{A}=\frac{2}{n}\left(\sum_{j=1}^{n-1} \psi\left(\lambda_{j}\right) \psi\left(\lambda_{j}\right)^{\prime}-\sum_{j=1}^{n-1} \psi\left(\lambda_{j}\right) \hat{\varepsilon}\left(\lambda_{j}\right)^{\prime} x\left(\sum_{j=1}^{n-1} \hat{\varepsilon}\left(\lambda_{j}\right) \hat{\varepsilon}\left(\lambda_{j}\right)^{\prime}\right)^{-1} x \sum_{j=1}^{n-1} \hat{\varepsilon}\left(\lambda_{j}\right) \psi\left(\lambda_{j}\right)^{\prime}\right) \\
\psi\left(\lambda_{j}\right)=\operatorname{Re}\left(\frac{\partial}{\partial \theta} \log \rho\left(e^{i \lambda_{j}} ; 0\right)\right) ; \quad \hat{\varepsilon}\left(\lambda_{j}\right)=\frac{\partial}{\partial \tau} \log g\left(\lambda_{j} ; \hat{\tau}\right)
\end{gathered}
$$

where the sum on ${ }^{*}$ is over $\lambda_{j}$ such that $-\pi<\lambda_{j}<\pi$. $\lambda_{j} \notin\left(\rho_{1}-\lambda_{1}, \rho_{1}+\lambda_{1}\right), 1=1,2$, $\ldots, \mathrm{s}$, such that $\rho_{1} 1=1,2, \ldots, \mathrm{s}<\infty$ are the distinct poles of $\rho(\mathrm{L})$. Note that $\hat{R}$ is a function of the hypothesized differenced series which has short memory under (11), and thus we must specify the frequencies and integration orders of any seasonal roots.

Robinson (1994) established under regularity conditions that

$$
\hat{R} \rightarrow_{d} \quad \chi_{p}^{2} \quad \text { as } n \rightarrow \infty,
$$

and also the Pitman efficiency property of LM in standard problems. If $p=1$, an approximate one-sided $100 \alpha \%$ level test of (11) against alternatives

$$
H_{1}: \theta>0 \text {. }
$$

rejects $H_{o}$ if $\hat{r}>z_{\alpha}$, where the probability that a standard normal variate exceeds $z_{\alpha}$ is $\alpha$, and conversely, a test of (11) against alternatives

$$
H_{1}: \theta<0
$$

rejects $H_{o}$ if $\hat{r}<-z_{\alpha}$. A test against the two-sided alternative $\theta \neq 0$, for any $p$, rejects if $\hat{R}$ exceeds the upper critical value of the $\chi_{p}^{2}$ distribution.

We can compare Robinson's (1994) tests with those in HEGY (1990). Extending (5) to allow augmentations of the dependent variable to render the errors white noise, and deterministic paths, the auxiliary regression in HEGY (1990) is

$$
\phi(L)\left(1-L^{4}\right) y_{t}=\pi_{1} y_{1 t-1}+\pi_{2} y_{2 t-1}+\pi_{3} y_{3 t-2}+\pi_{4} y_{3 t-1}+\eta_{t}+\varepsilon_{t},
$$

where $\phi(L)$ is a stationary lag polynomial and $\eta_{t}$ is a deterministic process that might include an intercept, a time trend and/or seasonal dummies. If we 
cannot reject the null hypothesis $\pi_{1}=0$ against the alternative $\pi_{1}<0$ in (15), the process will have a unit root at zero frequency whether or not other (seasonal) roots are present in the model. In Robinson's (1994) tests, taking (9) with

$$
\rho(L ; \theta)=(1-L)^{d+\theta}
$$

with $\mathrm{d}=1$, (11) implies a single unit root at zero frequency. However, we could have instead

$$
\rho(L ; \theta)=\left(1-L^{2}\right)^{d+\theta}
$$

or alternatively

$$
\rho(L ; \theta)=\left(1-L+L^{2}-L^{3}\right)^{d+\theta}
$$

or

$$
\rho(L ; \theta)=\left(1-L^{4}\right)^{d+\theta} .
$$

If again $\mathrm{d}=1$, under (11), $\mathrm{x}_{\mathrm{t}}$ displays unit roots at frequencies zero and $\pi$ in (17); zero and two complex ones corresponding to frequencies $\pi / 2$ and $3 \pi / 2$ in (18), or all of them in (19). Using HEGY's (1990) tests, the non-rejection of the null $\pi_{2}=0$ in (15) will imply a unit root at frequency $\pi$ independently of other possible roots, and this can be consistent with (8) - (10) jointly with (17) or (19) among other possibilities covered by Robinson's (1994) tests. Furthermore, testing sequentially, (or jointly as in Ghysels et al., 1994), the different null hypotheses in (15), if we cannot reject that $\pi_{i}=0$ for $i=1,2,3$ and 4 , the overall null hypothesized model in HEGY (1990) becomes

$$
\phi(L)\left(1-L^{4}\right) y_{t}=\eta_{t}+\varepsilon_{t}, \quad t=1,2, \ldots
$$

and we can compare it with the set-up in Robinson (1994), using (8) - (10) and (19) with $\phi(\mathrm{L}) \mathrm{u}_{\mathrm{t}}=\varepsilon_{\mathrm{t}^{\prime}} \mathrm{t}=1,2, \ldots$, which, with $\mathrm{d}=1$, under the null (11) becomes

$$
\phi(L)\left(1-L^{4}\right) y_{t}=\phi(L) \beta^{\prime}\left(1-L^{4}\right) z_{t}+\varepsilon_{t}, \quad t=1,2, \ldots .
$$

Clearly, if we do not include explanatory variables in (8) and (15), (i.e., $\eta_{t}=z_{t} \equiv$ $0)$, (21) becomes (20), and including regressors, the difference between the two models will be due purely to deterministic components. Robinson's (1994) tests also allow testing different integration orders for each of the seasonal frequencies. Thus, instead of (19) we could consider for instance,

$$
\rho(L ; \theta)=(1-L)^{d_{1}+\theta_{1}}(1+L)^{d_{2}+\theta_{2}}\left(1+L^{2}\right)^{d_{3}+\theta_{3}}
$$


and test the null $\theta=\left(\theta_{1}, \theta_{2}, \theta_{3}\right)^{\prime}=0$ for different values of $d_{1}, d_{2}$ and $d_{3}$. This possibility is also ruled out in HEGY (1990) and the other tests presented above, which just concentrate on the unit root situations.

We can also compare the tests of Robinson (1994) with those in Tam and Reinsel (1997). They considered (6) and (7), where $u_{t}$ is now a stationary and invertible ARMA process and tested

$$
H_{o}: \alpha=1
$$

in (7) against the alternative $\alpha<1$. The non-rejection of (23) in (6) and (7) would imply that $\mathrm{y}_{\mathrm{t}}$ follows a deterministic seasonal pattern plus a stationary stochastic process, while its rejection would be evidence of seasonal integration. We can take fractional operators instead of the AR and MA ones in (7):

$$
\left(1-L^{s}\right)^{d} y_{t}=\left(1-L^{s}\right)^{\gamma} u_{t}, \quad t=1,2, \ldots .
$$

with $d>0$, and given the common factors appearing in both sides in (24), calling $\delta=\gamma-\mathrm{d}$, the model can be rewritten as (6) with

$$
\left(1-L^{s}\right)^{\delta} y_{t}=u_{t}, \quad t=1,2, \ldots,
$$

and we can test $H_{o} \delta=0$ against the alternative $\delta>0$. Thus, (7) and (25) are identical under the null. The null and alternative versions of (25) are covered by Robinson's (1994) setting, with $\beta^{\prime} z_{t}$ in (8) replaced by $\mu_{t^{\prime}}$ and $s=4, d=0$ and $\theta=\delta$ in (19).

The null $\chi^{2}$ limit distribution of Robinson's (1994) tests is constant across specifications of $\rho(L ; \theta)$ and $z_{t}$ and thus does not require case by case evaluation of a nonstandard distribution, unlike of the other tests described. Ooms (1997) proposes Wald tests based on Robinson's (1994) model in (8) (10), which have the same limit behaviour as LM tests of Robinson (1994), but require efficient estimates of the fractional differencing parameters. He suggests a modified periodogram regression estimation procedure of Hassler (1994), whose distribution is evaluated under simulation. Also Hosoya (1997) establishes limit theory for long memory processes with singularities not restricted to zero frequency and proposes a set of quasi-log-likelihood ratio statistics to be applied to raw time series. Robinson's (1994) tests were applied 
to non-seasonal data by Gil-Alaña and Robinson (1997), and given the vast amount of empirical work based on AR structures, an empirical study of fractional-based tests for seasonal data seems overdue.

\section{Empirical applications}

The relationship between consumption and income is arguably one of the most important in macroeconomics. The most influential and perhaps most widely tested view of this relationship is the permanent income hypothesis (see Hall, 1989). We concentrate on the univariate treatment of these two variables, and apply different versions of Robinson's (1994) tests to some seasonally unadjusted, quarterly data for United Kingdom and Japan, using the same dataset as in HEGY (1990) and HEGL (1993) respectively.

For both countries we follow the same procedure. We test (11) in a version of (8),

$$
y_{t}=\beta_{1}+\beta_{2} t+\beta_{3} S_{1 t}+\beta_{4} S_{2 t}+\beta_{5} S_{3 t}+x_{t}, \quad t=1,2, \ldots
$$

with (9) and (10), where $S_{1 t^{\prime}} S_{2 t}$ and $S_{3 t}$ are seasonal dummies. We test in a sequential way. Since the data are quarterly, we start by assuming that $x_{t}$ in (26) has four roots and take $\rho(L ; \theta)$ as in (19). Given that $\theta$ is scalar, we test $H_{o}$ (11) against the one-sided alternatives (13) and (14). In order to allow different integration orders at different frequencies we also consider

$$
\rho(L ; \theta)=\left(1-L^{2}\right)^{d_{1}+\theta_{1}}\left(1+L^{2}\right)^{d_{2}+\theta_{2}},
$$

and more generally, (22). Therefore, $\theta=\left(\theta_{1}, \theta_{2}\right)^{\prime}$ under (27) and $\left(\theta_{1}, \theta_{2}, \theta_{3}\right)^{\prime}$ under (22) and we test here (11) against the two-sided alternative $\theta \neq 0$. Clearly, when departures are actually of the specialized form (19), a test of (11) directed against (19) will have greater power than ones directed against (27) or (22), but the tests have power against a wider range of alternatives.

Following this sequential way of testing we next assume $x_{t}$ displays only three roots: two of them complex, corresponding to frequencies $\pi / 2$ and $3 \pi / 2$, and one real that might be either at zero or at frequency $\pi$. Thus, we perform the tests in case of (18) and

$$
\rho(L ; \theta)=\left(1+L+L^{2}+L^{3}\right)^{d+\theta},
$$


and extending now the tests to allow different integration orders at the complex and at the real roots, we also consider two-sided tests where

$$
\rho(L ; \theta)=(1-L)^{d_{1}+\theta_{1}}\left(1+L^{2}\right)^{d_{2}+\theta_{2}}
$$

and

$$
\rho(L ; \theta)=(1+L)^{d_{1}+\theta_{1}}\left(1+L^{2}\right)^{d_{2}+\theta_{2}} .
$$

In a further group of tests, we assume that the hypothesized model contains only two roots, one at zero frequency and the other at $\pi$. Again we look first at one-sided tests against (17) and then at two-sided tests against

$$
\rho(L ; \theta)=(1-L)^{d_{1}+\theta_{1}}(1+L)^{d_{2}+\theta_{2}} .
$$

Finally we consider the possibility of a single root (or perhaps two complex ones), and therefore look at (16) as well as

$$
\rho(L ; \theta)=(1+L)^{d+\theta},
$$

and finally,

$$
\rho(L ; \theta)=\left(1+L^{2}\right)^{d+\theta} .
$$

The form of $\hat{A}$ for these various choices of $\rho$ is derived in the appendix. It is found that $\hat{A}$, interestingly, does not vary with the null hypothesized integration order $\mathrm{d}$ or integration orders $\mathrm{d}_{\mathrm{i}}$, clearly facilitating the computations. In all these cases the tests will be performed for different model specifications in (26). First, we assume that $\beta_{\mathrm{i}} \equiv 0$ a priori; next $\beta_{\mathrm{i}}=0, \mathrm{i} \geq 2$, (including an intercept); next $\beta_{\mathrm{i}}=0, \mathrm{i} \geq 3$, (a time trend); next $\beta_{2}=0$, (an intercept and dummy variables); finally that all $\beta_{\mathrm{i}}$ are unknown. In all cases we consider a wide range of null hypothesized $d$ (and $d_{i}$ 's when $p>1$ ), from 0.50 through 2.25 with 0.25 increments, and white noise $u_{t^{\prime}}$ though in some cases we extend to $\mathrm{I}(0)$ parametric autocorrelation in $\mathrm{u}_{\mathrm{t}}$. Clearly, non-rejections of (11) when $d$ (and the $d_{i}$ 's) equal 1 imply unit roots, and non-rejections with $d=$ 0 will suggest deterministic models of form advocated by Tam and Reinsel (1997).

\section{The U.K. case}

We analyze the quarterly United Kingdom dataset used in HEGY (1990). $c_{t}$ is $\log$ consumption expenditure on non-durables and $y_{t}$ is $\log$ 
personal disposable income, from 1955.1 through 1984.4. The conclusions of HEGY (1990) were that $c_{t}$ could be I(1) at each of the frequencies $0, \pi / 2$ (and $3 \pi / 2)$ and $\pi ; y_{t}$ may contain only two roots, at zero and $\pi ; c_{t}-y_{t}$ can have four unit roots if dummies are not introduced, but two unit roots of the same form as in $c_{t}$ if they are.

Table 1 reports results for the one-sided statistic $\hat{r}$, when $\rho(L ; \theta)$ in $(9)$ is (19). First, in Table 1(i), we take $u_{t}$ as a white noise process, and observe that for the two individual series $\left(c_{t}\right.$ and $\left.y_{t}\right)$, the null is never rejected when $d=0.75$ and $d=1$. Also, $d=1.25$ is not rejected when we include as regresors an intercept and dummies. For the differenced series $\left(c_{t}-y_{t}\right)$, the values of $d$ where $H_{o}$ is not rejected are slightly smaller $(d=0.50$ and $d=0.75)$, and the null hypothesis is clearly rejected in all cases, in favour of less nonstationary alternatives, suggesting that if the two individual series were in fact I(1), a degree of fractional integration may exist for a given cointegrating vector (1, 1), using a simplistic version of the "permanent income hypothesis theory" as discussed by Davidson et al. (1978) for example. The fact that the unit root null is never rejected for $c_{t}$ is consistent with HEGY (1990), but this hypothesis is not rejected for $\mathrm{y}_{\mathrm{t}}$, while HEGY (1990) found evidence of only two unit roots (at frequencies 0 and $\pi$ ) in this series. Various tests of this hypothesis will be performed later in a further group of tests. Also, HEGY (1990) introduced augmentations, including lagged values of the series. Thus, we also performed the tests with $A R u_{t^{t}}$. In Tables 1(ii) and (iii) we give results for $A R(1)$ and $A R(2)$ $u_{t}$ respectively. Tests allowing higher order AR $u_{t}$ were also performed, yielding similar results. The non-rejection values are now $d=0.50$ and $d=0.75$, and in those cases where the former is rejected, this is always in favour of stationary alternatives. The lower integration orders observed in these two tables compared with Table 1(i) can in large part be due to the fact that the AR estimates are Yule-Walker ones, entailing roots that cannot exceed one in absolute value but can be arbitrarily close to it, so they pick up part of the nonstationary component. 
Table 2 reports results of the two-sided tests $\hat{R}$ in (12) when $\theta$ is a (2x1) vector. $\rho(L ; \theta)$ is now given by $(27)$ and therefore we allow different integration orders for the real and complex roots, letting $d_{1}$ and $d_{2}$ take each of the values 0.50 (0.25) 1.50. We concentrate on the cases of no regressors, of an intercept, and of both, an intercept and a time trend, and present the results only for those cases where we observe at least one non-rejection value for each $\left(d_{1}, d_{2}\right)$ combination across the series. If there are no regressors, $\mathrm{H}_{\mathrm{o}}$ is rejected in all cases for the individual series, while for $c_{t}-y_{t}$ we observe several nonrejections when $\mathrm{d}_{1}=0.50,0.75,1.00$ and 1.25 and $\mathrm{d}_{2}=0.50$ and 0.75 . Including an intercept or a linear time trend, the results are similar in both cases, with most of the non-rejections occurring when $d_{2}$ is smaller than $d_{1}$, and also observing smaller orders for $c_{t}-y_{t}$ than for the individual series.

In Table 3 we extend these tests to allow different integration orders at zero and $\pi$, and thus $\rho(L ; \theta)$ is in (22). Again we only present the results for those cases where we observe at least one non-rejection value. The results are consistent with the previous ones: in fact, when there are no regressors, the null is always rejected for $c_{t}$ and $y_{t^{\prime}}$ while for $c_{t}-y_{t}$ there are some nonrejections, with the lowest value achieved at $\mathrm{d}_{1}=1$ and $\mathrm{d}_{2}=\mathrm{d}_{3}=0.50$. Including a constant or a time trend, the results seem to emphasize the importance of the root at zero frequency over the others, given its greater integration order.

Following this sequential way of testing we next assume $x_{t}$ can be modelled with three roots, and thus remove from (19) the root at zero frequency (in which case $\rho(L ; \theta)$ adopts the forms (28) or (30)), or at $\pi$ (i.e., $\rho(L$; $\theta$ ) as in (18) or (29)). Though we do not present the results, they show that $\mathrm{H}_{\mathrm{o}}$ is rejected in all series and across all cases, indicating the importance of these two roots, as suggested by HEGY (1990).

In the next group of tables we suppose $x_{t}$ has only two roots, at zero and $\pi$. First we take $\rho(L ; \theta)$ as in (17), so the same integration order is assumed at both frequencies. This way of specifying the model is interesting in view of the results in HEGY (1990), who suggested that only two unit roots at these frequencies were present in $y_{t}$ and in some cases for $c_{t}-y_{t}$. Results for white 
noise $u_{t}$ are given in Table 4 and the non-rejection values occur when $d=0.75$ and 1 for $c_{t}$ and $y_{t^{\prime}}$ and when $d=0.50$ for $c_{t}-y_{t^{\prime}}$ suggesting again the possibility of a fractional cointegrating relationship at these two frequencies with cointegrating vector $(1,-1)$. The hypothesis of two unit roots is always rejected for $c_{t}$ if we include regressors. These rejections are in line with HEGY (1990), who indicated that complex unit roots should be included. For $y_{t}$ we observe that $d=1$ is not rejected in 3 of the 5 possible specifications in (26), which is also consistent with HEGY (1990). If we allow integration orders to differ between zero and $\pi$ frequencies, (i.e., $\rho(L ; \theta)$ as in (31)), the only non-rejection values occur when $d_{1}=0.75$ and $d_{2}=0.50$ for $y_{t}$ with an intercept and with a linear time trend.

Finally we assume $x_{t}$ has only two complex roots, at $\pi / 2$ and $3 \pi / 2$, or a single one either at $\pi$ or zero. Thus $\rho(\mathrm{L} ; \theta)$ takes the form given in (33), (32) and (16) respectively. As expected, $\mathrm{H}_{\mathrm{o}}$ is always rejected in the first two cases, indicating the importance of the root at zero frequency to describe trending behaviour. Table 5 gives results of $\hat{r}$ for white noise $u_{t}$ and $\rho(L ; \theta)$ as in (16), and we observe that if there are no regressors the $I(1)$ null is not rejected for $c_{t}$ and $y_{t}$ but is strongly rejected for $c_{t}-y_{t}$. There are few non-rejections in this table and they correspond to values of $\mathrm{d}$ ranging between 0.50 and 1 for the individual series. For $c_{t}-y_{t^{\prime}}$ the only two non-rejection cases occur at $d=0.50$ if dummies are included, but for the remaining specifications this null is strongly rejected in favour of stationary alternatives. The fact that the unit root is rejected in this table for all series when some regressors are included in (26) is consistent with HEGY (1990), who suggested the need of at least one seasonal unit root.

Summarizing now the main results obtained in the U.K. case, we can say that if $x_{t}$ in (26) is $I(d)$ with four roots of the same order and $u_{t}$ is white noise, the values of $\mathrm{d}$ where the null is not rejected range between 0.75 and 1 for the individual series and are slightly smaller for the difference $c_{t}-y_{t}$. If $u_{t}$ is $\mathrm{AR}$, d ranges between 0.50 and 0.75 for the three series considered. Allowing different integration orders at each frequency, we observe that the root at zero 
frequency seems more important than the seasonal ones, at the seasonal root at $\pi$ appears also more important than the two complex ones at $\pi / 2$ and $3 \pi / 2$. If we take $x_{t}$ as $I(d)$ with two real roots, the model seems more appropriate for $y_{t}$ than for $c_{t}$ or $c_{t}-y_{t}$, which is in line with results in HEGY (1990). Finally, modelling $x_{t}$ as fractionally integrated with a single root at zero frequency, the range of $\mathrm{d}$ where $\mathrm{H}_{\mathrm{o}}$ is not rejected goes from 0.50 to 1 for the individual series but close to stationarity for $c_{t}-y_{t^{\prime}}$ but using a single seasonal root at frequency $\pi$ or a pair of complex ones at frequencies $\pi / 2$ and $3 \pi / 2$ seems inappropriate in view of the great proportion of rejections.

\section{The Japanese case}

We analyze here the log of total real consumption $\left(c_{t}\right)$, the log of real disposable income $\left(\mathrm{y}_{\mathrm{t}}\right)$, and the difference between them $\left(\mathrm{c}_{\mathrm{t}}-\mathrm{y}_{\mathrm{t}}\right)$ in Japan from 1961.1 to 1987.4 in 1980 prices. These series have been analyzed in HEGL (1993) to test the presence of seasonal integration and cointegration. In this work (and in an earlier version, HEGL, 1991), they apply the HEGY (1990) tests to these data and their conclusions can be summarized as follows: for $\mathrm{c}_{\mathrm{t}^{\prime}}$ a unit root is observed at all frequencies $0, \pi / 2,3 \pi / 2$ and $\pi$ if there are no regresssors in the model or if only a time trend is included; however, if dummies are also included, only two unit roots are observed, one at zero frequency and one at frequency $\pi$. For $y_{t}$, unit roots are not rejected at any frequency when there are no regressors or when a time trend and/or dummies are introduced, but if only an intercept is included the unit root at zero frequency is rejected. Finally, for $c_{t}-y_{t}$, unit root nulls are not rejected at any frequency, independently of the regressors used.

Table 6 is analogous to Table 1, showing the one-sided test statistic $\hat{r}$ when $\rho(L ; \theta)$ in (9) takes the form (19). Table 6 (i) reports results for white noise $\mathrm{u}_{\mathrm{t}^{\prime}}$ and the first thing that we observe is that if $\beta_{\mathrm{i}} \equiv 0$ in (26), we cannot reject (11) for $d=0.75$ and $d=1$ in case of either $c_{t}$ or $y_{t}$, while for $c_{t}-y_{t}$, these two cases are also not rejected, along with $d=0.50$. Including regressors, the unit root hypothesis is rejected in both series in favour of more nonstationary 
alternatives, while the nulls $d=0.75$ and $d=1$ are never rejected for $c_{t}-y_{t}$. Thus, if $\rho(L ; \theta)=1-L^{4}$ and $u_{t}$ is white noise, the two individual series are clearly nonstationary with $d$ greater than 1 in most cases; however, their difference seems less nonstationary, suggesting that some fractional cointegration could exist between both series, with cointegrating vector $(1,-1)$. The fact that $d=1$ is not rejected for $c_{t}$ and $y_{t}$ when there are no regressors, and for $c_{t}-y_{t}$ independently of the regressors used in (26), is consistent with the results in HEGL (1993) though they allow AR structure in the differenced series. Therefore in Tables 6 (ii) and (iii) we suppose that $u_{t}$ in (9) is an AR(q) with $\mathrm{q}=1$ or 2 . The range of non-rejection values of $\mathrm{d}$ goes from 0.50 through 1 for $c_{t}$ and $c_{t}-y_{t}$ and from 0.50 through 1.25 for $y_{t}$. As we explained before for the U.K. case, this smaller degree in the integration order of the series (compared with Table 6 (i)), could be in large part due to competition between integration order and AR parameters in describing the nonstationary component. If we concentrate on the $\operatorname{AR}(1)$, we see that the unit root is not rejected for $y_{t}$ but is for $c_{t}$ when dummy variables are included in the model, again in line with HEGL (1993).

So far we have assumed that the four roots in $x_{t}$ must have the same integration order. In the following tables we allow integration orders to differ between complex roots and real ones. Table 7 corresponds to two-sided tests when $\rho(\mathrm{L} ; \theta)$ in (9) takes the form given in (27). When there are no regressors, the null is rejected in all cases for both $c_{t}$ and $y_{t^{\prime}}$ while for $c_{t}-y_{t}$ we observe some non-rejections when $\mathrm{d}_{1}=\mathrm{d}_{2}=0.50,0.75$ and 1 . These three possibilities were not rejected in Table 6 (i) when we employed the one-sided tests. Including an intercept or a time trend, we observe now some non-rejections for $c_{t}$ and $y_{t}$. Starting with $c_{t}, H_{o}$ is not rejected when $d_{1}=1.25$ or 1.50 and $d_{2}=0.50$, 0.75 and 1 , observing therefore a greater degree of integration at zero and $\pi$ frequencies than at $\pi / 2$ and $3 \pi / 2$. Similarly, for $y_{t^{\prime}}$ all non-rejections occur when $d_{1}$ is slightly greater than $d_{2}$, and for $c_{t}-y_{t}$, the lowest statistics are obtained at $\mathrm{d}_{1}=\mathrm{d}_{2}=0.75$. The null hypothesis of a unit root at all frequencies is 
not rejected in this series, which is again consistent with Table 6 (i) and with results of HEGL (1993).

In Table 8 we are slightly more general in the specification of $\rho(L ; \theta)$ in (9), and a different integration order is allowed at each frequency. Therefore, $\rho(L ; \theta)$ takes the form (22). Similarly to Table 7 , when there are no regressors the null is always rejected for the individual series, while for $c_{t}-y_{t}$ there are non-rejections at some alternatives, with $\mathrm{d}_{1}$ greater than $\mathrm{d}_{2}$ or $\mathrm{d}_{3}$. Including an intercept or a time trend, the results emphasize the importance of the root at zero frequency over the others for the three series.

Performing the tests under the assumption that $\rho(L ; \theta)$ is of forms (18) or (28) - (30), we always rejected. Thus, following this sequential way of performing the tests, we next assume that $x_{t}$ has only two roots, one at zero frequency and the other at $\pi$. First we take $\rho(L ; \theta)$ as in (17), so $\theta$ consists of a single parameter. Table 9 gives results for one-sided tests with white noise $u_{t}$. We observe that the results are quite variable across the different specifications of (26), and while the orders of integration range between 0.50 and 1.25 for the individual series, for the difference $c_{t}-y_{t}$ the only non-rejections occur when $d$ $=0.50$ with seasonal dummies. The results for the unit root case are consistent with those in HEGL (1993). In fact, the unit root null is not rejected for $c_{t}$ when dummies are included, but is nearly always rejected for $y_{t}$ and $c_{t}-y_{t^{\prime}}$ due perhaps to exclusion of unit roots at frequencies $\pi / 2$ and $3 \pi / 2$, as was suggested by these authors. Extending the tests to allow different integration orders at the same two frequencies, we observed just a single case where the null was not rejected and it corresponded to $c_{t}$ with no regressors and $d_{1}=1.25$ and $\mathrm{d}_{2}=0.50$.

Finally, we examine the case of $x_{t}$ containing a single root, and concentrate on the case when this root is at zero frequency, i.e. (16). Table 10 shows results merely for white noise $u_{t^{\prime}}$ and we observe that the unit root null is not rejected for $c_{t}$ and $y_{t}$ when there are no regressors, but strongly rejected for $c_{t}-y_{t}$. In fact, in the latter series the null is rejected in favour of stationary 
alternatives for the whole variety of specifications in (26), suggesting that at this zero frequency, a certain degree of fractional cointegration might also occur, with reference again to the permanent income hypothesis. Modelling $x_{t}$ with a single root at frequency $\pi$ (i.e. (32)) or as an $I(d)$ process with two complex roots corresponding to frequencies $\pi / 2$ and $3 / 2$ (i.e., (33)), produced rejections for all cases and across all series.

In conclusion we can summarize the main results obtained for the Japanese case by saying that if $x_{t}$ is $I(d)$ with four seasonal roots of the same order $d$, and $u_{t}$ is white noise, the values of $d$ where the null is not rejected are at least one for $c_{t}$ and $y_{t^{\prime}}$ and less than or equal to one for $c_{t}-y_{t}$ If $u_{t}$ is $A R, d$ ranges in most cases from 0.50 to 1 for the three series, and, allowing different integration orders for the different frequencies, the most noticeable fact is the relative importance of the root at zero frequency over the others. Taking $x_{t}$ as $\mathrm{I}(\mathrm{d})$ with two roots, at zero and at frequency $\pi$, the null is not rejected for $c_{t}$ when $d$ ranges between 0.75 and 1.25 while for $y_{t}$ and $c_{t}-y_{t^{\prime}}$ the non-rejection cases correspond to $d<1$. Finally, if we assume that $x_{t}$ has a single root at zero frequency or at frequency $\pi$ (or two complex ones corresponding to frequencies $\pi / 2$ and $3 \pi / 2$ ), the unit root hypothesis will be rejected in practically all cases in favour of less nonstationary alternatives.

\section{Concluding remarks}

Our approach, based on Robinson (1994), has the advantage over standard autoregressive-based methods of allowing for fractional components, different memory parameters across seasonal frequencies, and of standard null limit distribution theory and Pitman efficiency against local alternatives. Our Lagrange multiplier testing avoids estimation of parameters under the alternative hypothesis, unlike Wald and likelihood-ratio type tests, while, possessing the same null and local limit behaviour as such tests. In the empirical work, we select a wide range of null hypotheses, with respect to memory parameter, instead of estimating them, and the results may give some impression of the local power performance of the tests. 
We have presented a variety of model specifications for quarterly consumption and income data in Japan and U.K.. Given the variety of possibilities covered by Robinson's (1994) tests, one cannot expect to draw unambiguous conclusions about the very best way of modelling these series. In fact, using these tests, the null hypothesized model will permit different deterministic paths; different lagged structures allowing roots at some or all seasonal frequencies, each of them with a possibly different integration order; and different ways of modelling the $\mathrm{I}(0)$ disturbances $\mathrm{u}_{\mathrm{t}}$. Looking at the results presented above as a whole, some common features are observed for all series in both countries, however, and they can be summarized as follows:

First, modelling $x_{t}$ as a quarterly $I(d)$ process, we observe that integration orders are slightly smaller if $u_{t}$ is AR rather than white noise, due perhaps to the AR component picking up part of the nonstationary component. The results emphasize the importance of real roots over complex ones, given the greater integration order observed for the former, and this is even clearer when we allow different integration orders for each frequency. Excluding one real root results in rejecting the null in practically all situations. If $\rho(L ; \theta)$ is given by $(17)$, we observe several non-rejections, and separating the roots at zero and at $\pi$, the results emphasize the importance of the root at zero. Modelling the series, however, as a simple I(d) process with a single root does not seem appropriate in most of the cases.

Another common feature observed across all the tables is the fact that integration orders for the individual series seem to range between 0.50 (or 0.75) and 1.25 , independently of the lag function $\rho(L ; \theta)$ used when modelling $x_{t}$ in (9) and the inclusion or not of deterministic paths in (26), indicating clearly the nonstationary nature of these series. In fact, though this was not shown in the tables, the null was practically always rejected when $\mathrm{d}$ ranged between 0 and 0.50, and therefore we found conclusive evidence against deterministic patterns of the form proposed by Tam and Reinsel (1997); however, $c_{t}-y_{t}$ seems less integrated in practically all cases. Therefore, if we consider that the series are well modelled by a given function $\rho(L ; \theta)$, a certain degree of fractional cointegration would exist between consumption and income for a 
given cointegrated vector $(1,-1)$, using a very simplistic version of the permanent income hypothesis.

We can finally compare these results with those obtained in HEGL (1993) and HEGY (1990) for unit root situations. Results in HEGL (1993) for Japanese data indicated the presence of unit roots at all frequencies for $y_{t}$ and $c_{t}$ $-y_{t}$ and the same conclusions hold for $c_{t}$ if dummies are excluded, though only two real unit roots would be present if these dummy variables are included. Looking now at our tables, we observe that the unit root null is not rejected for $y_{t}$ in any specification in (26) when $\rho(L ; \theta)$ adopts the form (19) with AR $u_{t}$. Similarly, for $c_{t}-y_{t}$ we cannot reject the unit root null for the same $\rho(L ; \theta)$ and white noise $\mathrm{u}_{\mathrm{t}}$. For $\mathrm{c}_{\mathrm{t}^{\prime}}$, the null of four unit roots is not rejected when there are no dummies, but if these are included non-rejections will occur when $\rho(L ; \theta)$ takes the form (17). For the U.K. case, results in HEGY (1990) suggested that four unit roots could be present for $c_{t}$, and for $c_{t}-y_{t}$ if dummies are excluded, and two real unit roots for $y_{t}$ and for $c_{t}-y_{t}$ if they are included. Our results again show a certain consistency with theirs, given that the unit root null is not rejected for consumption if $\rho(L ; \theta)$ is (19) with white noise $u_{t}$, and for income this hypothesis is not rejected if $\rho(L ; \theta)$ takes the form (17).

\section{Appendix}

In this appendix we analyze the matrix $\hat{A}$ in $\hat{R}$ in (12) when $\rho(\mathrm{L} ; \theta)$ in (9) adopts the form in (22) and $u_{t}$ is white noise, so that

$$
\hat{A}=\frac{2}{n} \sum_{j}^{*} \psi\left(\lambda_{j}\right) \psi\left(\lambda_{j}\right)^{\prime},
$$

where $\psi\left(\lambda_{j}\right)=\left(\psi_{1}\left(\lambda_{j}\right), \psi_{2}\left(\lambda_{j}\right), \psi_{3}\left(\lambda_{j}\right)\right)^{\prime}$ for $|\lambda| \leq \pi$, with

$$
\begin{gathered}
\psi_{1}\left(\lambda_{j}\right)=\operatorname{Re}\left[\log \left(1-e^{i \lambda}\right)\right]=\log \left|2 \sin \frac{\lambda}{2}\right|=-\sum_{r=1}^{\infty} \frac{\cos r \lambda}{r}, \\
\psi_{2}\left(\lambda_{j}\right)=\operatorname{Re}\left[\log \left(1+e^{i \lambda}\right)\right]=\log \left(2 \cos \frac{\lambda}{2}\right)=-\sum_{r=1}^{\infty}(-1)^{r} \frac{\cos r \lambda}{r}, \\
\psi_{3}\left(\lambda_{j}\right)=\operatorname{Re}\left[\log \left(1+e^{2 i \lambda}\right)\right]=\log |2 \cos \lambda|=-\sum_{r=1}^{\infty}(-1)^{r} \frac{\cos 2 r \lambda}{r} .
\end{gathered}
$$


Then $\hat{A}$ can be approximated in large samples by $\widetilde{A}=\frac{1}{\pi} \int_{-\pi}^{\pi} \psi(\lambda) \psi(\lambda)^{\prime} d \lambda=\left(\tilde{A}_{i j}\right)$, where

$$
\begin{gathered}
\widetilde{A}_{11}=\widetilde{A}_{22}=\widetilde{A}_{33}=\sum_{r=1}^{\infty} r^{-2} \approx \frac{\pi^{2}}{6}=1.644, \\
\widetilde{A}_{13}=\widetilde{A}_{31}=\widetilde{A}_{23}=\widetilde{A}_{32}=\frac{1}{2} \sum_{r=1}^{\infty}(-1)^{r} r^{-2} \approx-0.411, \\
\widetilde{A}_{12}=\widetilde{A}_{21}=\sum_{r=1}^{\infty}(-1)^{r} r^{-2} \approx-0.822 .
\end{gathered}
$$

$\hat{A}$ in (12) approximates $\mathrm{n}$ times the expected value of the second derivative matrix of the Gaussian log-likelihood with respect to the (px1) parameter vector $\theta$. (See, Robinson, 1994, page 1433). Thus, given the non-diagonality of $\hat{A}$, we rule out the possibility of testing, as in HEGY (1990), for the presence of roots independently of the existence of other roots at any other frequencies in the process.

For the remaining specifications of $\rho(\mathrm{L} ; \theta), \widetilde{A}$ can be easily obtained from the above expressions. Thus, if $\rho(L ; \theta)$ is given by $(19), \psi(\lambda)=\psi_{1}(\lambda)+\psi_{2}(\lambda)$ $+\psi_{3}(\lambda)$ and $\tilde{A}=1.64$; under $(27), \psi(\lambda)=\left[\psi_{1}(\lambda)+\psi_{2}(\lambda), \psi_{3}(\lambda)\right]^{\prime}$ and the $(2 \times 2)$ matrix $\widetilde{A}=\left[(1.64,-0.82)^{\prime} ;(-0.82,1.64)^{\prime}\right] ;$ under $(18), \psi(\lambda)=\psi_{1}(\lambda)+\psi_{3}(\lambda)$ and $\tilde{A}$ $=2.46$; under (28), $\psi(\lambda)=\psi_{2}(\lambda)+\psi_{3}(\lambda)$ and $\tilde{A}=2.46$; under $(29), \psi(\lambda)=\left[\psi_{1}(\lambda)\right.$, $\left.\psi_{3}(\lambda)\right]^{\prime}$ and $\tilde{A}=\left[(1.64,-0.41)^{\prime} ;(-0.41,1.64)^{\prime}\right] ;$ under $(30), \psi(\lambda)=\left[\psi_{2}(\lambda), \psi_{3}(\lambda)\right]^{\prime}$ and $\widetilde{A}=\left[(1.64,-0.41)^{\prime} ;(-0.41,1.64)^{\prime}\right] ;$ under $(17), \psi(\lambda)=\psi_{1}(\lambda)+\psi_{2}(\lambda)$ and $\tilde{A}=$ 1.64; under (31), $\psi(\lambda)=\left[\psi_{1}(\lambda), \psi_{2}(\lambda)\right]^{\prime}$ and $\widetilde{A}=\left[(1.64,-0.82)^{\prime} ;(-0.82,1.64)^{\prime}\right]$; under (16), (32) or (33), $\psi(\lambda)=\psi_{1}(\lambda), \psi_{2}(\lambda)$ or $\psi_{3}(\lambda)$ respectively, with $\widetilde{A}=1.64$ in each case.

Allowing $\operatorname{AR}(q) u_{t}, g(\lambda ; \tau)$ below (10) takes the form

$$
\left|1-\sum_{j=1}^{q} \tau_{j} e^{i j \lambda}\right|^{-2},
$$

and $\hat{A}$ will be given by the expression below (12), with the $1^{\text {th }}$ element of $\hat{\varepsilon}(\lambda)$ given by 


$$
\hat{\varepsilon}_{l}(\lambda)=2\left(\cos l \lambda-\sum_{j=1}^{q} \hat{\tau}_{j} \cos (l-j)\right) g(\lambda ; \hat{\tau}) .
$$

A diskette containing the FORTRAN codes for the tests can be obtained from the first author upon request and it is also available in Gil-Alaña (1997), pages 155-167 and on the JAE web site. 


\section{References}

Bealieu, J.J. and J.A. Miron (1993), 'Seasonal unit roots in aggregate U.S. data', Journal of Econometrics, 55, 305-331.

Box, G.E.P. and G.M. Jenkins (1970), Time series analysis: Forecasting and Control, San Francisco: Holden-Day.

Canova, F. and B.E. Hansen (1995), 'Are seasonal patterns constant over time? A test for seasonal stability', Journal of Business and Economic Statistics, 13, 237252.

Carlin, J.B. and A.P. Dempster (1989), 'Sensitivity analysis of seasonal adjustments: empirical case studies', Journal of the American Statistical Association, 84, 6-20.

Carlin, J.B., A.P. Dempster and A.B. Jonas (1985), 'On methods and models for Bayesian time series analysis', Journal of Econometrics, 30, 67-90.

Davidson, J.E., D.F. Hendry, F. Srba and S. Yeo (1978), 'Econometric modelling of aggregate time series relationships between consumer's expenditure and income in the U.K.', Economic Journal, 91, 704-715.

Dickey, D.A., D.P. Hasza and W.A. Fuller (1984), 'Testing for unit roots in seasonal time series', Journal of the American Statistical Association, 79, 355-367.

Fuller, W.A. (1976), Introduction to statistical time series, Willey Series in Probability and Mathematical Statistics, Willey, New York, NY.

Ghysels, E., H.S. Lee and J. Noh (1994), 'Testing for unit roots in seasonal time series: some theoretical extensions and a Monte Carlo investigation', Journal of Econometrics, 62, 415-443.

Gil-Alaña, L.A. (1997), 'Testing fractional integration in macroeconomic time series', Ph. D. thesis, London School of Economics, University of London, London.

Gil-Alaña, L.A. and P.M. Robinson (1997), 'Testing of unit roots and other nonstationary hypotheses in macroeconomic time series', Journal of Econometrics, 80, 241-268.

Hall, R.E. (1989), Consumption, modern business cycle theory, ed. R.J. Barro, Cambridge, Harvard University Press.

Hassler, U. (1994), 'Misspecification of long memory seasonal time series', Journal of Time Series Analysis, 15, 19-30. 
Hosoya, Y. (1997), 'A limit theory for long-range dependence and statistical inference on related models', Annals of Statistics, 25, 105-137.

Hylleberg, S. (1995), 'Tests for seasonal unit roots. General to specific or specific to general', Journal of Econometrics, 69, 5-25.

Hylleberg, S., R.F. Engle, C.W.J. Granger and H.S. Lee (1991), 'Seasonal cointegration. The Japanese consumption function, 1961.1 - 1987.4', Discussion Paper, University of California, San Diego, C.A.

Hylleberg, S., R.F. Engle, C.W.J. Granger and H.S. Lee (1993), 'Seasonal cointegration. The Japanese consumption function', Journal of Econometrics, 55, 275-298.

Hylleberg, S., R.F. Engle, C.W.J. Granger and B.S. Yoo (1990), 'Seasonal integration and cointegration', Journal of Econometrics, 44, 215-238.

Hylleberg, S., C. Jorgensen and N.K. Sorensen (1993), 'Seasonality in macroeconomic time series', Empirical Economics, 18, 321-335.

Jonas, A.B. (1981), 'Long memory self similar time series models', unpublished manuscript, Harvard University, Dept. of Statistics.

Kwiatkowski, D., P.C.B. Phillips, P. Schmidt and Y. Shin (1992), 'Testing the null hypothesis of stationary against the alternative of a unit root', Journal of Econometrics, 54, 159-166.

Ooms, M. (1997), 'Flexible seasonal long memory and economic time series', Preprint.

Osborn, D.R. (1993), 'Discussion of Engle et al., 1993', Journal of Econometrics, 55, 299-303.

Porter-Hudak, S. (1990), 'An application of the seasonal fractionally differenced model to the monetary aggregate', Journal of the American Statistical Association, 85, 338-344.

Ray, B.K. (1993), 'Long range forecasting of IBM product revenues using a seasonal fractionally differencing ARMA model', International Journal of Forecasting, 9, 255-269.

Robinson, P.M. (1994), 'Efficient tests of nonstationary hypotheses' Journal of the American Statistical Association, 89, 1420-1437.

Sutcliffe, A. (1994), 'Time series forecasting using fractional differencing', Journal of Forecasting, 13, 383-393.

Tam, W. and G.C. Reinsel (1997), 'Tests for seasonal moving average unit root in ARIMA models', Journal of the American Statistical Association, 92, 725-738. 


\section{TABLE 1}

$\hat{r}$ in (12) with $\rho(L ; \theta)=\left(1-L^{4}\right)^{d+\theta}$ for the U.K. data

i): With white noise $\mathrm{u}_{\mathrm{t}}$

\begin{tabular}{|c|c|c|c|c|c|c|c|c|c|}
\hline Series & $\mathrm{z}_{\mathrm{t}} / \mathrm{d}$ & 0.50 & 0.75 & 1.00 & 1.25 & 1.50 & 1.75 & 2.00 & 2.25 \\
\hline \multirow{5}{*}{$c_{t}$} & --- & 3.31 & $1.02^{\prime}$ & $-1.00^{\prime}$ & -2.43 & -3.32 & -3.88 & -4.25 & -4.51 \\
\hline & $\mathrm{I}$ & 5.09 & $1.31^{\prime}$ & $-1.11^{\prime}$ & -2.00 & -2.79 & -3.42 & -3.86 & -4.18 \\
\hline & $\mathrm{I}, \mathrm{T}$ & 2.65 & $0.41^{\prime}$ & $-1.26^{\prime}$ & -2.33 & -3.02 & -3.46 & -3.75 & -3.99 \\
\hline & $\mathrm{I}, \mathrm{S}$ & 5.17 & $1.32^{\prime}$ & $-1.09^{\prime}$ & $-1.87^{\prime}$ & -2.62 & -3.24 & -3.70 & -4.04 \\
\hline & $\mathrm{I}, \mathrm{T}, \mathrm{S}$ & 2.70 & $0.31^{\prime}$ & $-1.25^{\prime}$ & -2.23 & -2.87 & -3.34 & -3.72 & -4.04 \\
\hline \multirow{5}{*}{$Y_{t}$} & ב--- & 3.29 & $1.01^{\prime}$ & '-1.00' & -2.42 & -3.31 & -3.87 & -4.24 & $\begin{array}{c}-4.50 \\
\end{array}$ \\
\hline & I & 5.16 & $1.25^{\prime}$ & $-0.96^{\prime}$ & $-1.81^{\prime}$ & -2.61 & -3.25 & -3.72 & -4.08 \\
\hline & $\mathrm{I}, \mathrm{T}$ & 2.50 & $0.45^{\prime}$ & $-1.06^{\prime}$ & -2.11 & -2.84 & -3.37 & -3.76 & -4.07 \\
\hline & $\mathrm{I}, \mathrm{S}$ & 5.16 & $1.21^{\prime}$ & $-0.97^{\prime}$ & $-1.76^{\prime}$ & -2.53 & -3.16 & -3.64 & -4.00 \\
\hline & $\mathrm{I}, \mathrm{T}, \mathrm{S}$, & 2.41 & $0.39^{\prime}$ & $0.39^{\prime}$ & -2.06 & -2.76 & -3.28 & -3.69 & -4.02 \\
\hline \multirow{5}{*}{$c_{t}-y_{t}$} & ב--- & $-0.66^{\prime}$ & $\begin{array}{l}-1.48^{\prime} \\
\end{array}$ & -2.21 & -2.84 & -3.32 & -3.69 & -3.99 & $\begin{array}{l}-4.24 \\
\end{array}$ \\
\hline & I & $1.09^{\prime}$ & $-1.37^{\prime}$ & -2.39 & -3.05 & -3.53 & -3.88 & -4.15 & -4.37 \\
\hline & $\mathrm{I}, \mathrm{T}$ & $-0.20^{\prime}$ & $-1.44^{\prime}$ & -2.39 & -3.06 & -3.53 & -3.86 & -4.11 & -4.32 \\
\hline & $\mathrm{I}, \mathrm{S}$ & $1.34^{\prime}$ & $-1.19^{\prime}$ & -2.21 & -2.89 & -3.41 & -3.79 & -4.08 & -4.32 \\
\hline & $\mathrm{I}, \mathrm{T}, \mathrm{S}$ & $-0.01^{\prime}$ & -1.26 & -2.21 & -2.92 & -3.43 & -3.82 & -4.11 & -4.35 \\
\hline \multicolumn{10}{|c|}{ ii): With $\operatorname{AR}(1) \mathrm{u}_{\mathrm{t}}$} \\
\hline Series & $\mathrm{z}_{\mathrm{t}} / \mathrm{d}$ & 0.50 & 0.75 & 1.00 & 1.25 & 1.50 & 1.75 & 2.00 & 2.25 \\
\hline \multirow{5}{*}{$\mathrm{C}_{\mathrm{t}}$} & --- & -3.26 & -3.62 & -3.96 & -4.27 & -4.52 & -4.72 & -4.87 & -4.98 \\
\hline & $\mathrm{I}$ & $-0.84^{\prime}$ & $-0.78^{\prime}$ & -2.10 & -3.13 & -3.76 & -4.17 & -4.44 & -4.63 \\
\hline & $\mathrm{I}, \mathrm{T}$ & $1.07^{\prime}$ & $-0.82^{\prime}$ & -2.32 & -3.25 & -3.81 & -4.16 & -4.39 & -4.55 \\
\hline & $\mathrm{I}, \mathrm{S}$ & -2.27 & -2.65 & -3.34 & -3.75 & -4.05 & -4.29 & -4.49 & -4.65 \\
\hline & $\mathrm{I}, \mathrm{T}, \mathrm{S}$, & -1.08 & -2.64 & -3.38 & -3.81 & -4.10 & -4.32 & -4.50 & -4.65 \\
\hline \multirow{5}{*}{$Y_{t}$} & $\begin{array}{c}-- \\
\end{array}$ & -3.26 & -3.62 & -3.96 & -4.27 & -4.52 & -4.71 & -4.86 & -4.98 \\
\hline & I & $-1.81^{\prime}$ & $-1.77^{\prime}$ & -2.59 & -3.32 & -3.85 & -4.23 & -4.49 & $\begin{array}{l}-4.69 \\
\end{array}$ \\
\hline & $\mathrm{I}, \mathrm{T}$ & $-0.24^{\prime}$ & $-1.69^{\prime}$ & -2.69 & -3.40 & -3.90 & -4.25 & -4.50 & -4.68 \\
\hline & $\mathrm{I}, \mathrm{S}$ & -2.43 & -2.52 & -3.01 & -3.47 & -3.87 & -4.18 & -4.43 & -4.62 \\
\hline & $\mathrm{I}, \mathrm{T}, \mathrm{S}$ & $-1.23^{\prime}$ & -2.32 & -2.99 & -3.51 & -3.90 & -4.21 & -4.44 & -4.63 \\
\hline \multirow{5}{*}{$c_{t}-y_{t}$} & --- & $-0.86^{\prime}$ & $-1.85^{\prime}$ & -2.60 & -3.17 & -3.59 & -3.91 & -4.17 & $\begin{array}{l}-4.38 \\
\end{array}$ \\
\hline & I & $-0.30^{\prime}$ & $-1.79^{\prime}$ & -2.66 & -3.25 & -3.69 & -4.01 & -4.25 & -4.45 \\
\hline & $\mathrm{I}, \mathrm{T}$ & $-0.62^{\prime}$ & $-1.80^{\prime}$ & -2.66 & -3.26 & -3.69 & -3.99 & -4.22 & -4.41 \\
\hline & $\mathrm{I}, \mathrm{S}$ & $-0.29^{\prime}$ & $-1.67^{\prime}$ & -2.52 & -3.13 & -3.58 & -3.93 & -4.20 & -4.41 \\
\hline & $\mathrm{I}, \mathrm{T}, \mathrm{S}$, & $-0.57^{\prime}$ & $-1.69^{\prime}$ & -2.52 & -3.14 & -3.60 & -3.94 & -4.21 & -4.43 \\
\hline
\end{tabular}

iii): With $\operatorname{AR}(2) u_{t}$

\begin{tabular}{|c|c|c|c|c|c|c|c|c|c|}
\hline Series & $z_{t} / d$ & 0.50 & 0.75 & 1.00 & 1.25 & 1.50 & 1.75 & 2.00 & 2.25 \\
\hline \multirow{5}{*}{$c_{t}$} & --- & -3.30 & -3.62 & -3.91 & -4.21 & -4.48 & -4.69 & -4.85 & -4.98 \\
\hline & $\mathrm{I}$ & $-1.11^{\prime}$ & $-1.10^{\prime}$ & -2.25 & -3.18 & -3.77 & -4.16 & -4.42 & -4.61 \\
\hline & $\mathrm{I}, \mathrm{T}$ & $0.45^{\prime}$ & $-1.17^{\prime}$ & -2.47 & -3.32 & -3.85 & -4.18 & -4.39 & -4.54 \\
\hline & $\mathrm{I}, \mathrm{S}$ & -2.35 & -2.80 & -3.49 & -3.88 & -4.15 & -4.36 & -4.54 & -4.68 \\
\hline & $\mathrm{I}, \mathrm{T}, \mathrm{S}$, & $-1.29^{\prime}$ & -2.81 & -3.53 & -3.93 & -4.20 & -4.39 & -4.55 & -4.68 \\
\hline \multirow{5}{*}{$\mathrm{y}_{\mathrm{t}}$} & --- & -3.29 & -3.61 & -3.91 & -4.21 & -4.47 & -4.68 & -4.85 & -4.98 \\
\hline & $\mathrm{I}$ & -2.13 & -2.27 & -2.89 & -3.47 & -3.92 & -4.26 & -4.51 & -4.69 \\
\hline & $\mathrm{I}, \mathrm{T}$ & $-1.10^{\prime}$ & -2.19 & -2.96 & -3.54 & -3.97 & -4.29 & -4.51 & -4.69 \\
\hline & $\mathrm{I}, \mathrm{S}$ & -2.62 & -2.81 & -3.20 & -3.59 & -3.92 & -4.20 & -4.43 & -4.61 \\
\hline & $\mathrm{I}, \mathrm{T}, \mathrm{S}$, & $-1.79^{\prime}$ & -2.64 & -3.18 & -3.61 & -3.95 & -4.23 & -4.45 & -4.62 \\
\hline \multirow{5}{*}{$c_{t}-y_{t}$} & --- & $-0.90^{\prime}$ & -2.02 & -2.79 & -3.31 & -3.69 & -3.97 & -4.20 & -4.40 \\
\hline & $\mathrm{I}$ & $-0.68^{\prime}$ & -1.99 & -2.83 & -3.39 & -3.78 & -4.07 & -4.29 & -4.47 \\
\hline & $\mathrm{I}, \mathrm{T}$ & $-0.71^{\prime}$ & -1.96 & -2.82 & -3.39 & -3.78 & -4.06 & -4.27 & -4.44 \\
\hline & $\mathrm{I}, \mathrm{S}$ & $-0.69^{\prime}$ & $-1.90^{\prime}$ & -2.72 & -3.29 & -3.70 & -4.02 & -4.26 & -4.46 \\
\hline & $\mathrm{I}, \mathrm{T}, \mathrm{S}$, & $-0.67^{\prime}$ & $-1.88^{\prime}$ & -2.71 & -3.29 & -3.71 & -4.03 & -4.28 & -4.47 \\
\hline
\end{tabular}

': Non-rejection values for the null hypothesis (11) at 95\% significance level; --: No intercept, no time trend and no seasonal dummies; I: Intercept; I,T: Intercept and time trend; I,S: Intercept and seasonal dummies; I,T,S: Intercept, time trend and seasonal dummies. 
TABLE 2

\begin{tabular}{|c|c|c|c|c|c|c|c|c|c|c|}
\hline \multicolumn{8}{|c|}{$\hat{R}$ in $(12)$ with $\rho(L ; \theta)=\left(1-L^{2}\right)^{d_{1}+\theta_{1}}\left(1+L^{2}\right)^{d_{2}+\theta_{2}}$ and white noise $\mathrm{u}_{\mathrm{t}}$ for the U.K. data } \\
\hline \multicolumn{1}{|c|}{} & \multicolumn{2}{|c|}{ No intercept and no trend } & \multicolumn{3}{c|}{ Intercept } & \multicolumn{2}{c|}{ Intercept and a time trend } \\
\hline $\mathrm{d}_{1}$ & $\mathrm{~d}_{2}$ & $\mathrm{c}_{\mathrm{t}}$ & $\mathrm{y}_{\mathrm{t}}$ & $\mathrm{c}_{\mathrm{t}}-\mathrm{y}_{\mathrm{t}}$ & $\mathrm{c}_{\mathrm{t}}$ & $\mathrm{y}_{\mathrm{t}}$ & $\mathrm{c}_{\mathrm{t}}-\mathrm{y}_{\mathrm{t}}$ & $\mathrm{c}_{\mathrm{t}}$ & $\mathrm{y}_{\mathrm{t}}$ & $\mathrm{c}_{\mathrm{t}}-\mathrm{y}_{\mathrm{t}}$ \\
\hline 0.50 & 0.50 & 52.45 & 52.15 & $3.42^{\prime}$ & 79.34 & 83.17 & 11.36 & 33.55 & 40.66 & $3.65{ }^{\prime}$ \\
\hline 0.75 & 0.50 & 19.80 & 19.76 & $1.05^{\prime}$ & 12.96 & 18.85 & $0.86^{\prime}$ & 7.51 & 14.80 & $0.86^{\prime}$ \\
\hline 0.75 & 0.75 & 25.89 & 25.85 & $5.65^{\prime}$ & 23.48 & 26.73 & $4.90^{\prime}$ & 16.69 & 21.37 & $4.82^{\prime}$ \\
\hline 1.00 & 0.50 & 8.31 & 8.29 & $2.03^{\prime}$ & $0.86^{\prime}$ & $5.43^{\prime}$ & $2.76^{\prime}$ & $1.03^{\prime}$ & $5.61^{\prime}$ & $2.75^{\prime}$ \\
\hline 1.00 & 0.75 & 11.56 & 11.57 & $4.20^{\prime}$ & 6.07 & 10.23 & $4.48^{\prime}$ & 6.47 & 10.40 & $4.46^{\prime}$ \\
\hline 1.25 & 0.50 & 8.60 & 8.55 & $4.99^{\prime}$ & $0.98^{\prime}$ & $3.89^{\prime}$ & $5.88^{\prime}$ & $1.36^{\prime}$ & 4.47 & $5.91^{\prime}$ \\
\hline 1.25 & 0.75 & 10.58 & 10.56 & $5.34^{\prime}$ & $4.14^{\prime}$ & 7.44 & 6.20 & $4.78^{\prime}$ & 7.98 & 6.26 \\
\hline 1.50 & 0.50 & 11.09 & 11.01 & 8.22 & $2.96^{\prime}$ & $5.40^{\prime}$ & 8.93 & $3.22^{\prime}$ & 6.04 & 8.89 \\
\hline 1.50 & 0.75 & 12.97 & 12.92 & 7.49 & $5.14^{\prime}$ & 8.19 & 8.41 & $5.57^{\prime}$ & 8.93 & 8.37 \\
\hline
\end{tabular}

: Non-rejection values for the null hypothesis (11) at 95\% significance level.

\section{TABLE 3}

$\hat{R}$ in (12) with $\rho(L ; \theta)=(1-L)^{d_{1}+\theta_{1}}(1+L)^{d_{2}+\theta_{2}}\left(1+L^{2}\right)^{d_{3}+\theta_{3}}$ and white noise $\mathrm{u}_{\mathrm{t}}$ for the U.K. data

\begin{tabular}{|c|c|c|c|c|c|c|c|c|c|c|c|}
\hline \multicolumn{4}{|c|}{} & \multicolumn{3}{c|}{ No intercept and no trend } & \multicolumn{3}{c|}{ Intercept } & \multicolumn{3}{c|}{ Intercept and a time trend } \\
\hline $\mathrm{d}_{1}$ & $\mathrm{~d}_{2}$ & $\mathrm{~d}_{3}$ & $\mathrm{c}_{\mathrm{t}}$ & $\mathrm{y}_{\mathrm{t}}$ & $\mathrm{c}_{\mathrm{t}}-\mathrm{y}_{\mathrm{t}}$ & $\mathrm{c}_{\mathrm{t}}$ & $\mathrm{y}_{\mathrm{t}}$ & $\mathrm{c}_{\mathrm{t}}-\mathrm{y}_{\mathrm{t}}$ & $\mathrm{c}_{\mathrm{t}}$ & $\mathrm{y}_{\mathrm{t}}$ & $\mathrm{c}_{\mathrm{t}}-\mathrm{y}_{\mathrm{t}}$ \\
\hline 1.00 & 0.50 & 0.50 & 21.14 & 21.23 & $2.00^{\prime}$ & $2.11^{\prime}$ & $7.68^{\prime}$ & $3.10^{\prime}$ & $2.15^{\prime}$ & 7.91 & $3.05^{\prime}$ \\
\hline 1.00 & 1.00 & 0.50 & 34.51 & 34.56 & $4.70^{\prime}$ & 11.11 & 23.34 & 4.20 & 11.61 & 24.20 & $4.21{ }^{\prime}$ \\
\hline 1.50 & 1.00 & 0.50 & 15.57 & 15.54 & $6.04^{\prime}$ & $2.54^{\prime}$ & $6.03^{\prime}$ & 6.53 & $2.62^{\prime}$ & $6.32^{\prime}$ & 6.50 \\
\hline 1.50 & 1.50 & 0.50 & 20.77 & 20.74 & 8.93 & $6.09^{\prime}$ & 12.07 & 9.28 & 6.03 & 12.23 & 9.24 \\
\hline
\end{tabular}

': Non-rejection values for the null hypothesis (11) at 95\% significance level. 


\begin{tabular}{|c|c|c|c|c|c|c|c|c|c|}
\hline \multicolumn{10}{|c|}{ TABLE 4} \\
\hline \multicolumn{10}{|c|}{$\hat{r}$ in $(12)$ with $\rho(L ; \theta)=\left(1-L^{2}\right)^{d+\theta}$ and white noise $\mathrm{u}_{\mathrm{t}}$ for the U.K. data } \\
\hline Series & $z_{t} / d$ & 0.50 & 0.75 & 1.00 & 1.25 & 1.50 & 1.75 & 2.00 & 2.25 \\
\hline \multirow{5}{*}{$c_{t}$} & -- & 5.23 & 2.04 & $-0.47^{\prime}$ & -2.00 & -2.87 & $\begin{array}{l}-3.38 \\
\end{array}$ & -3.72 & -3.95 \\
\hline & I & 2.06 & -4.26 & -4.74 & -4.86 & -4.95 & -5.01 & -5.04 & -5.06 \\
\hline & $\mathrm{I}, \mathrm{T}$ & -3.21 & -4.30 & -4.71 & -4.89 & -4.98 & -5.03 & -5.06 & -5.09 \\
\hline & $\mathrm{I}, \mathrm{S}$ & 7.14 & $0.17^{\prime}$ & -2.49 & -3.40 & -3.98 & $\begin{array}{l}-4.33 \\
\end{array}$ & $\begin{array}{l}-4.53 \\
\end{array}$ & -4.66 \\
\hline & $\mathrm{I}, \mathrm{T}, \mathrm{S}$ & 2.60 & $-0.66^{\prime}$ & -2.50 & $\begin{array}{l}-3.48 \\
\end{array}$ & -4.03 & \begin{tabular}{|l|l|}
-4.34 \\
\end{tabular} & -4.54 & -4.66 \\
\hline \multirow{5}{*}{$\mathrm{y}_{\mathrm{t}}$} & --- & 5.18 & 2.00 & $-0.51^{\prime}$ & -2.03 & -2.89 & -3.40 & -3.74 & -3.97 \\
\hline & I & 6.47 & $-0.69^{\prime}$ & -2.81 & -3.64 & -4.16 & -4.47 & -4.65 & -4.76 \\
\hline & $\mathrm{I}, \mathrm{T}$ & 1.99 & $-1.05^{\prime}$ & -2.80 & -3.72 & $\begin{array}{l}-4.23 \\
\end{array}$ & $\begin{array}{l}-4.49 \\
\end{array}$ & -4.65 & -4.76 \\
\hline & $\mathrm{I}, \mathrm{S}$ & 7.52 & $1.52^{\prime}$ & $-1.16^{\prime}$ & -2.38 & -3.23 & -3.75 & -4.07 & -4.28 \\
\hline & $\mathrm{I}, \mathrm{T}, \mathrm{S}$ & 4.09 & $0.96^{\prime}$ & $-1.18^{\prime}$ & -2.50 & -3.29 & -3.78 & -4.08 & -4.28 \\
\hline \multirow{5}{*}{$c_{t}-y_{t}$} & -- & -3.97 & -4.47 & -4.77 & -4.93 & -5.01 & -5.05 & -5.07 & -5.08 \\
\hline & I & -3.11 & -4.35 & -4.70 & -4.86 & -4.94 & $\begin{array}{l}-4.98 \\
\end{array}$ & $\begin{array}{l}-5.01 \\
\end{array}$ & -5.03 \\
\hline & $\mathrm{I}, \mathrm{T}$ & -3.76 & $\begin{array}{l}-4.40 \\
\end{array}$ & -4.70 & -4.86 & -4.94 & $\begin{array}{l}-4.99 \\
\end{array}$ & $\begin{array}{l}-5.02 \\
\end{array}$ & -5.04 \\
\hline & $\mathrm{I}, \mathrm{S}$ & $-0.54^{\prime}$ & -3.03 & -3.84 & -4.27 & -4.51 & -4.66 & -4.75 & -4.82 \\
\hline & $\mathrm{I}, \mathrm{T}, \mathrm{S}$ & $-1.64^{\prime}$ & -3.06 & -3.85 & -4.27 & -4.51 & -4.66 & -4.75 & -4.81 \\
\hline
\end{tabular}

$\because$ : Non-rejection values for the null hypothesis (11) at $95 \%$ significance level. --: No intercept, no time trend and no seasonal dummies; I: An intercept; I,T: An intercept and a time trend; I,S: An intercept and seasonal dummies; I,S,T: An intercept, a time trend and seasonal dummies.

\begin{tabular}{|c|c|c|c|c|c|c|c|c|c|}
\hline \multicolumn{10}{|c|}{ TABLE 5} \\
\hline \multicolumn{10}{|c|}{$\hat{r}$ in $(12)$ with $\rho(L ; \theta)=(1-L)^{d+\theta}$ and white noise $\mathrm{u}_{\mathrm{t}}$ for the U.K. data } \\
\hline Series & $\mathrm{z}_{\mathrm{t}} / \mathrm{d}$ & 0.50 & 0.75 & 1.00 & 1.25 & 1.50 & 1.75 & 2.00 & 2.25 \\
\hline \multirow{5}{*}{$c_{t}$} & -- & 9.89 & 3.91 & $-0.30^{\prime}$ & -2.55 & -3.73 & -4.43 & -4.87 & -5.18 \\
\hline & I & $1.57^{\prime}$ & -4.49 & -4.76 & $\begin{array}{l}-5.01 \\
\end{array}$ & $\begin{array}{l}-5.23 \\
\end{array}$ & -5.42 & $\begin{array}{l}-5.59 \\
\end{array}$ & $\begin{array}{l}-5.74 \\
\end{array}$ \\
\hline & $\mathrm{I}, \mathrm{T}$ & -3.32 & -4.31 & -4.74 & -5.02 & -5.25 & -5.44 & -5.61 & -5.76 \\
\hline & $\mathrm{I}, \mathrm{S}$ & 11.91 & $-0.91^{\prime}$ & -3.37 & -4.28 & -4.83 & -5.18 & -5.42 & -5.61 \\
\hline & $\mathrm{I}, \mathrm{T}, \mathrm{S}$ & 3.84 & $-1.13^{\prime}$ & $\begin{array}{l}-3.34 \\
\end{array}$ & $\begin{array}{l}-4.34 \\
\end{array}$ & -4.87 & -5.21 & -5.45 & -5.64 \\
\hline \multirow{5}{*}{$y_{t}$} & --- & $\begin{array}{l}9.83 \\
\end{array}$ & 3.87 & $-0.31^{\prime}$ & -2.55 & $\begin{array}{l}-3.73 \\
\end{array}$ & -4.42 & $\begin{array}{l}-4.86 \\
\end{array}$ & -5.17 \\
\hline & I & 8.65 & -3.00 & -4.31 & -4.95 & -5.37 & -5.65 & -5.85 & -6.00 \\
\hline & $\mathrm{I}, \mathrm{T}$ & $1.13^{\prime}$ & -2.69 & -4.27 & -4.99 & -5.41 & -5.67 & -5.87 & -6.02 \\
\hline & $\mathrm{I}, \mathrm{S}$ & 11.76 & $-0.86^{\prime}$ & $\begin{array}{l}-3.49 \\
\end{array}$ & $\begin{array}{l}-4.60 \\
\end{array}$ & -5.24 & -5.61 & -5.85 & -6.02 \\
\hline & $\mathrm{I}, \mathrm{T}, \mathrm{S}$ & 4.76 & $-0.77^{\prime}$ & -3.44 & -4.66 & -5.28 & -5.64 & -5.87 & -6.04 \\
\hline \multirow{5}{*}{$c_{t}-y_{t}$} & -- & -3.66 & -4.26 & $\begin{array}{l}-4.63 \\
\end{array}$ & -4.87 & -5.06 & -5.22 & -5.38 & -5.52 \\
\hline & I & -3.00 & -4.20 & -4.61 & -4.87 & -5.07 & -5.24 & -5.40 & -5.54 \\
\hline & $\mathrm{I}, \mathrm{T}$ & -3.50 & -4.23 & $\begin{array}{l}-4.61 \\
\end{array}$ & -4.87 & -5.07 & $\begin{array}{l}-5.24 \\
\end{array}$ & $\begin{array}{l}-5.39 \\
\end{array}$ & $\begin{array}{l}-5.54 \\
\end{array}$ \\
\hline & $\mathrm{I}, \mathrm{S}$ & $-1.09^{\prime}$ & -3.67 & $\begin{array}{l}-4.42 \\
\end{array}$ & -4.85 & -5.13 & $\begin{array}{l}-5.34 \\
\end{array}$ & -5.51 & -5.65 \\
\hline & $\mathrm{I}, \mathrm{T}, \mathrm{S}$ & $-1.95^{\prime}$ & -3.63 & -4.42 & -4.85 & -5.13 & -5.34 & -5.50 & -5.65 \\
\hline
\end{tabular}

$\because$ : Non-rejection values for the null hypothesis (11) at $95 \%$ significance level. --: No intercept, no time trend and no seasonal dummies; I: An intercept; I,T: An intercept and a time trend; I,S: An intercept and seasonal dummies; I,S,T: An intercept, a time trend and seasonal dummie 


\section{TABLE 6}

$\hat{r}$ in (12) with $\rho(L ; \theta)=\left(1-L^{4}\right)^{d+\theta}$ for the Japanese data

i): With white noise $u_{t}$

\begin{tabular}{|c|c|c|c|c|c|c|c|c|c|}
\hline Series & $\mathrm{z}_{\mathrm{t}} / \mathrm{d}$ & 0.50 & 0.75 & 1.00 & 1.25 & 1.50 & 1.75 & 2.00 & 2.25 \\
\hline \multirow{5}{*}{$c_{t}$} & --- & 2.61 & $0.77^{\prime}$ & $-1.02^{\prime}$ & -2.36 & -3.22 & -3.76 & -4.12 & -4.37 \\
\hline & $\mathrm{I}$ & 4.36 & 2.64 & 3.05 & $1.36^{\prime}$ & $-0.89^{\prime}$ & -2.54 & -3.50 & -4.04 \\
\hline & $\mathrm{I}, \mathrm{T}$ & 9.12 & 7.28 & 3.83 & $0.008^{\prime}$ & -2.72 & -3.76 & -4.01 & -4.17 \\
\hline & $\mathrm{I}, \mathrm{S}$ & 4.41 & 2.80 & 4.39 & 2.95 & $0.34^{\prime}$ & $-1.78^{\prime}$ & -3.06 & -3.76 \\
\hline & $\mathrm{I}, \mathrm{T}, \mathrm{S}$, & 10.02 & 8.34 & 5.14 & $1.04^{\prime}$ & -2.11 & -3.51 & -3.99 & -4.24 \\
\hline \multirow{5}{*}{$\mathrm{y}_{\mathrm{t}}$} & "--- & 2.54 & $0.72^{\prime}$ & $-1.05^{\prime}$ & -2.38 & -3.23 & -3.77 & -4.13 & -4.38 \\
\hline & $\mathrm{I}$ & 4.70 & 3.34 & 2.21 & $-0.08^{\prime}$ & -2.10 & -3.37 & -4.06 & -4.44 \\
\hline & $\mathrm{I}, \mathrm{T}$ & 7.80 & 6.04 & 2.54 & $-0.91^{\prime}$ & -3.11 & -3.76 & -3.77 & -3.86 \\
\hline & $\mathrm{I}, \mathrm{S}$ & 4.95 & 4.12 & 4.78 & 2.33 & $-0.57^{\prime}$ & -2.63 & -3.72 & -4.25 \\
\hline & $\mathrm{I}, \mathrm{T}, \mathrm{S}$, & 10.28 & 8.48 & 5.10 & $0.84^{\prime}$ & -2.30 & -3.69 & -4.19 & -4.44 \\
\hline \multirow{5}{*}{$c_{t}-y_{t}$} & ב--- & $1.53^{\prime}$ & "-0.08' & $2-1.77^{\prime}$ & -2.93 & -3.63 & -4.05 & -4.33 & -4.52 \\
\hline & I & 2.41 & $0.46^{\prime}$ & $-1.54^{\prime}$ & -2.84 & -3.60 & -4.05 & -4.34 & -4.54 \\
\hline & $\mathrm{I}, \mathrm{T}$ & 2.34 & $0.45^{\prime}$ & $-1.54^{\prime}$ & -2.86 & -3.58 & -3.82 & -3.89 & -4.02 \\
\hline & $\mathrm{I}, \mathrm{S}$ & 3.42 & $0.35^{\prime}$ & $-1.79^{\prime}$ & -3.06 & -3.76 & -4.15 & -4.39 & -4.55 \\
\hline & $\mathrm{I}, \mathrm{T}, \mathrm{S}$ & 3.31 & $0.34^{\prime}$ & $-1.79^{\prime}$ & -3.06 & -3.76 & -4.15 & -4.39 & -4.55 \\
\hline \multicolumn{10}{|c|}{ ii): With $\operatorname{AR}(1) \mathrm{u}_{\mathrm{t}}$} \\
\hline Series & $\mathrm{z}_{\mathrm{t}} / \mathrm{d}$ & 0.50 & 0.75 & 1.00 & 1.25 & 1.50 & 1.75 & 2.00 & 2.25 \\
\hline \multirow{5}{*}{$c_{t}$} & --- & -3.13 & -3.50 & -3.83 & -4.13 & -4.38 & -4.57 & -4.71 & -4.83 \\
\hline & $\mathrm{I}$ & $-1.59^{\prime}$ & $-0.67^{\prime}$ & $-0.51^{\prime}$ & $-1.79^{\prime}$ & -2.78 & -3.50 & -3.99 & -4.30 \\
\hline & $\mathrm{I}, \mathrm{T}$ & 2.57 & $1.01^{\prime}$ & $-0.65^{\prime}$ & -2.01 & -3.19 & -3.82 & -4.09 & -4.27 \\
\hline & $\mathrm{I}, \mathrm{S}$ & -2.87 & -3.21 & -3.31 & -3.51 & -3.73 & -4.05 & -4.35 & -4.56 \\
\hline & $\mathrm{I}, \mathrm{T}, \mathrm{S}$, & $-1.05^{\prime}$ & -2.67 & -3.30 & -3.63 & -4.12 & -4.48 & -4.64 & -4.74 \\
\hline \multirow{5}{*}{$Y_{t}$} & --- & -3.01 & -3.47 & -3.82 & -4.12 & -4.37 & -4.57 & -4.71 & -4.83 \\
\hline & I & $-0.03^{\prime}$ & $0.87^{\prime}$ & $0.23^{\prime}$ & $-1.38^{\prime}$ & -2.67 & -3.52 & -4.03 & -4.34 \\
\hline & $\mathrm{I}, \mathrm{T}$ & 3.09 & 2.07 & $0.24^{\prime}$ & $-1.64^{\prime}$ & -3.09 & -3.67 & -3.80 & -3.96 \\
\hline & $\mathrm{I}, \mathrm{S}$ & -2.51 & -2.37 & $-1.71^{\prime}$ & $-1.88^{\prime}$ & -2.50 & -3.34 & -3.99 & -4.36 \\
\hline & $\mathrm{I}, \mathrm{T}, \mathrm{S}$ & $0.29^{\prime}$ & $-1.41^{\prime}$ & $-1.61^{\prime}$ & -1.98 & -3.08 & -3.91 & -4.28 & -4.49 \\
\hline \multirow{5}{*}{$c_{t}-y_{t}$} & --- & $0.87^{\prime}$ & $-0.84^{\prime}$ & -2.29 & -3.21 & -3.77 & -4.13 & -4.37 & $\begin{array}{l}-4.54 \\
\end{array}$ \\
\hline & I & 1.94' & $-0.01^{\prime}$ & $-1.78^{\prime}$ & -2.91 & -3.59 & -4.01 & -4.28 & -4.48 \\
\hline & $\mathrm{I}, \mathrm{T}$ & $1.89^{\prime}$ & $-0.02^{\prime}$ & $-1.78^{\prime}$ & -2.93 & -3.58 & -3.86 & -4.00 & -4.16 \\
\hline & $\mathrm{I}, \mathrm{S}$ & $1.34^{\prime}$ & $-1.29^{\prime}$ & -2.66 & -3.46 & -3.95 & -4.25 & -4.44 & -4.58 \\
\hline & $\mathrm{I}, \mathrm{T}, \mathrm{S}$, & $1.29^{\prime}$ & $-1.29^{\prime}$ & -2.66 & -3.46 & -3.95 & -4.25 & -4.45 & -4.58 \\
\hline
\end{tabular}

iii): With $\operatorname{AR}(2) u_{t}$

\begin{tabular}{|c|c|c|c|c|c|c|c|c|c|}
\hline Series & $\mathrm{z}_{\mathrm{t}} / \mathrm{d}$ & 0.50 & 0.75 & 1.00 & 1.25 & 1.50 & 1.75 & 2.00 & 2.25 \\
\hline \multirow{5}{*}{$\mathrm{c}_{\mathrm{t}}$} & --- & -3.19 & -3.53 & -3.81 & -4.09 & -4.34 & -4.54 & -4.70 & -4.82 \\
\cline { 2 - 10 } & $\mathrm{I}$ & $-1.53^{\prime}$ & $-0.51^{\prime}$ & $-0.85^{\prime}$ & -2.14 & -2.96 & -3.56 & -4.01 & -4.36 \\
\cline { 2 - 10 } & $\mathrm{I}, \mathrm{T}$ & $1.77^{\prime}$ & $0.16^{\prime}$ & $-1.35^{\prime}$ & -2.37 & -3.30 & -3.88 & -4.15 & -4.34 \\
\cline { 2 - 10 } & $\mathrm{I}, \mathrm{S}$ & -2.90 & -3.26 & -3.56 & -3.82 & -3.99 & -4.24 & -4.48 & -4.66 \\
\cline { 2 - 10 } & $\mathrm{I}, \mathrm{T}, \mathrm{S}$, & $-1.23^{\prime}$ & -2.84 & -3.60 & -3.92 & -4.29 & -4.60 & -4.74 & -4.83 \\
\hline \hline \multirow{5}{*}{$\mathrm{y}_{\mathrm{t}}$} & --- & -3.08 & -3.50 & -3.80 & -4.09 & -4.34 & -4.54 & -4.70 & -4.82 \\
\cline { 2 - 10 } & $\mathrm{I}$ & $-0.29^{\prime}$ & $0.75^{\prime}$ & 0.20 & -1.31 & -2.54 & -3.41 & -3.96 & -4.30 \\
\cline { 2 - 10 } & $\mathrm{I}, \mathrm{T}$ & 2.69 & $1.61^{\prime}$ & 0.04 & $-1.55^{\prime}$ & -3.04 & -3.66 & -3.77 & -3.93 \\
\cline { 2 - 10 } & $\mathrm{I}, \mathrm{S}$ & -2.54 & -2.57 & -2.53 & -2.78 & -3.05 & -3.57 & -4.07 & -4.39 \\
\cline { 2 - 10 } & $\mathrm{I}, \mathrm{T}, \mathrm{S}$, & $0.11^{\prime}$ & -1.99 & -2.59 & -2.72 & -3.33 & -3.97 & -4.31 & -4.51 \\
\hline \hline \multirow{5}{*}{$\mathrm{c}_{\mathrm{t}}-\mathrm{y}_{\mathrm{t}}$} & --- & 0.80 & $-0.88^{\prime}$ & -2.27 & -3.18 & -3.75 & -4.11 & -4.36 & -4.53 \\
\cline { 2 - 10 } & $\mathrm{I}$ & $1.85^{\prime}$ & $0.03^{\prime}$ & -1.72 & -2.89 & -3.60 & -4.02 & -4.30 & -4.49 \\
\cline { 2 - 10 } & $\mathrm{I}, \mathrm{T}$ & $1.81^{\prime}$ & $-0.01^{\prime}$ & $-1.72^{\prime}$ & -2.91 & -3.59 & -3.85 & -3.97 & -4.12 \\
\cline { 2 - 10 } & $\mathrm{I}, \mathrm{S}$ & $0.45^{\prime}$ & $-1.67^{\prime}$ & -2.77 & -3.47 & -3.94 & -4.24 & -4.44 & -4.58 \\
\cline { 2 - 10 } & $\mathrm{I}, \mathrm{T}, \mathrm{S}$, & $0.40^{\prime}$ & $-1.68^{\prime}$ & -2.77 & -3.47 & -3.94 & -4.24 & -4.44 & -4.58 \\
\hline
\end{tabular}

' $:$ Non-rejection values for the null hypothesis (11) at 95\% significance level; --: No intercept, no time trend and no seasonal dummies; I: Intercept; I,T: Intercept and time trend; I,S: Intercept and seasonal dummies; I,T,S: Intercept, time trend and seasonal dummies. 


\section{TABLE 7}

\begin{tabular}{|c|c|c|c|c|c|c|c|c|c|c|}
\hline \multicolumn{11}{|c|}{$\hat{R}$ in $(12)$ with $\rho(L ; \theta)=\left(1-L^{2}\right)^{d_{1}+\theta_{1}}\left(1+L^{2}\right)^{d_{2}+\theta_{2}}$ and white noise $\mathrm{u}_{\mathrm{t}}$ for the Japanese data } \\
\hline & & \multicolumn{3}{|c|}{ No intercept and no trend } & \multicolumn{3}{|c|}{ Intercept } & \multicolumn{3}{|c|}{ Intercept and a time trend } \\
\hline $\mathrm{d}_{1}$ & $\mathrm{~d}_{2}$ & $\mathrm{c}_{\mathrm{t}}$ & $\mathrm{y}_{\mathrm{t}}$ & $c_{t}-y_{t}$ & $\mathrm{c}_{\mathrm{t}}$ & $\mathrm{y}_{\mathrm{t}}$ & $c_{t}-y_{t}$ & $c_{t}$ & $\mathrm{y}_{\mathrm{t}}$ & $\mathrm{c}_{\mathrm{t}}-\mathrm{y}_{\mathrm{t}}$ \\
\hline 0.50 & 0.50 & 41.03 & 39.76 & $5.25^{\prime}$ & 64.79 & 63.91 & 6.83 & 167.85 & 107.69 & 6.49 \\
\hline 0.75 & 0.50 & 17.12 & 16.72 & $0.42^{\prime}$ & 22.81 & 13.95 & $4.30^{\prime}$ & 77.49 & 29.81 & $4.23^{\prime}$ \\
\hline 0.75 & 0.75 & 22.42 & 22.01 & $2.95^{\prime}$ & 34.46 & 30.38 & $0.50^{\prime}$ & 117.38 & 68.97 & $0.52^{\prime}$ \\
\hline 0.75 & 1.00 & 27.06 & 26.61 & 8.97 & 42.28 & 43.89 & $5.08^{\prime}$ & 137.50 & 100.85 & $5.26^{\prime}$ \\
\hline 1.00 & 0.50 & 7.76 & 7.64 & $3.58^{\prime}$ & 8.74 & 8.21 & 10.28 & 11.04 & 8.56 & 10.27 \\
\hline 1.00 & 0.75 & 10.73 & 10.62 & $1.45^{\prime}$ & 22.43 & $5.76^{\prime}$ & $2.66^{\prime}$ & 29.89 & 6.90 & $2.67^{\prime}$ \\
\hline 1.00 & 1.00 & 13.33 & 13.22 & $4.71^{\prime}$ & 35.55 & 14.50 & $2.39^{\prime}$ & 48.00 & 18.11 & $2.41^{\prime}$ \\
\hline 1.00 & 1.25 & 15.72 & 15.59 & 7.98 & 45.91 & 26.86 & $4.86^{\prime}$ & 62.37 & 33.81 & $4.89^{\prime}$ \\
\hline 1.25 & 0.50 & 8.07 & 7.98 & 8.32 & $1.82^{\prime}$ & 11.98 & 15.19 & $1.96^{\prime}$ & 14.05 & 15.31 \\
\hline 1.25 & 0.75 & 9.93 & 9.91 & $4.61^{\prime}$ & $3.85^{\prime}$ & 2.95 & 7.92 & $0.36^{\prime}$ & $5.22^{\prime}$ & 8.04 \\
\hline 1.25 & 1.00 & 11.30 & 11.30 & 6.64 & 11.73 & $0.30^{\prime}$ & 6.31 & $5.01^{\prime}$ & $0.43^{\prime}$ & 6.41 \\
\hline 1.25 & 1.25 & 12.40 & 12.40 & 9.30 & 20.03 & $4.29^{\prime}$ & 8.09 & 10.88 & $2.47^{\prime}$ & 8.20 \\
\hline 1.50 & 0.50 & 10.37 & 10.25 & 12.16 & $3.37^{\prime}$ & 16.22 & 18.62 & 6.01 & 19.15 & 19.08 \\
\hline 1.50 & 0.75 & 12.16 & 12.13 & 7.72 & $0.37^{\prime}$ & 9.18 & 11.92 & $3.78^{\prime}$ & 14.25 & 12.22 \\
\hline 1.50 & 1.00 & 13.30 & 13.31 & 8.85 & $2.37^{\prime}$ & $3.32^{\prime}$ & 9.31 & $5.14^{\prime}$ & 7.65 & 9.29 \\
\hline 1.50 & 1.25 & 13.99 & 14.02 & 11.58 & 6.04 & $3.81^{\prime}$ & 11.01 & 7.96 & 8.00 & 10.92 \\
\hline .50 & 1.50 & 14.45 & 14.48 & 13.53 & 9.44 & $5.56^{\prime}$ & 13.00 & 9.94 & 9.71 & 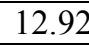 \\
\hline
\end{tabular}

': Non-rejection values for the null hypothesis (11) at 95\% significance level.

\begin{tabular}{|c|c|c|c|c|c|c|c|c|c|c|c|}
\hline \multicolumn{12}{|c|}{ TABLE 8} \\
\hline \multicolumn{12}{|c|}{$\begin{array}{c}\hat{R} \text { in }(12) \text { with } \rho(L ; \theta)=(1-L)^{d_{1}+\theta_{1}}(1+L)^{d_{2}+\theta_{2}}\left(1+L^{2}\right)^{d_{3}+\theta_{3}} \text { and white noise } \mathrm{u}_{\mathrm{t}} \text { for the Japanese } \\
\text { data }\end{array}$} \\
\hline & & & \multicolumn{3}{|c|}{ No intercept and no trend } & \multicolumn{3}{|c|}{ Intercept } & \multicolumn{3}{|c|}{ Intercept and a time trend } \\
\hline $\mathrm{d}_{1}$ & $\mathrm{~d}_{2}$ & $\mathrm{~d}_{3}$ & $c_{t}$ & $\mathrm{y}_{\mathrm{t}}$ & $c_{t}-y_{t}$ & $c_{t}$ & $\mathrm{y}_{\mathrm{t}}$ & $c_{t}-y_{t}$ & $c_{t}$ & $\mathrm{y}_{\mathrm{t}}$ & $c_{t}-y_{t}$ \\
\hline 1.00 & 0.50 & 0.50 & 18.90 & 18.50 & 2.03 & 9.87 & 3.73 & 4.01 & 10.73 & $3.66^{\prime}$ & 4.01 \\
\hline 1.00 & 0.50 & 1.00 & 29.47 & 28.91 & 2.04 & 32.10 & $4.74^{\prime}$ & $0.53^{\prime}$ & 36.42 & 4.94 & $0.54^{\prime}$ \\
\hline 1.00 & 0.50 & 1.50 & 38.39 & 37.60 & 3.03 & 45.26 & 8.71 & 1.04 & 50.98 & 8.85 & 1.04 \\
\hline 1.00 & 1.00 & 0.50 & 31.34 & 30.89 & $6.50^{\prime}$ & 24.98 & 12.03 & 11.13 & 28.27 & 12.33 & 11.12 \\
\hline 1.50 & 0.50 & 0.50 & 10.33 & 10.11 & $2.94^{\prime}$ & 9.57 & $3.89^{\prime}$ & 3.94 & 11.15 & $4.33^{\prime}$ & $3.99^{\prime}$ \\
\hline 1.50 & 0.50 & 1.00 & 13.25 & 13.06 & $1.78^{\prime}$ & 31.88 & $3.95^{\prime}$ & $1.19^{\prime}$ & 35.86 & $4.40^{\prime}$ & $1.20^{\prime}$ \\
\hline 1.50 & 0.50 & 1.50 & 14.41 & 14.16 & $2.00^{\prime}$ & 44.10 & 5.65 & 1.34 & 48.52 & 6.02 & 1.35 \\
\hline 1.50 & 1.00 & 0.50 & 14.23 & 14.01 & 11.25 & 3.24 & 14.26 & 16.43 & $4.79^{\prime}$ & 16.22 & 16.73 \\
\hline 1.50 & 1.00 & 1.00 & 19.69 & 19.56 & 7.84 & $3.62^{\prime}$ & $1.58^{\prime}$ & $7.17^{\prime}$ & $3.57^{\prime}$ & $3.72^{\prime}$ & $7.13^{\prime}$ \\
\hline 1.50 & 1.00 & 1.50 & 23.28 & 23.11 & 11.94 & 11.54 & $5.77^{\prime}$ & 10.30 & 9.18 & 8.36 & 10.26 \\
\hline 1.50 & 1.50 & 0.50 & 19.04 & 18.81 & 12.79 & 5.20 & 16.52 & 18.79 & $6.49^{\prime}$ & 19.23 & 19.22 \\
\hline 1.50 & 1.50 & 1.00 & 27.05 & 26.95 & 12.38 & 14.48 & 6.84 & 10.62 & 9.75 & 8.65 & 10.47 \\
\hline
\end{tabular}

' $:$ Non-rejection values for the null hypothesis (11) at $95 \%$ significance level. 
TABLE 9

$\hat{r}$ in (12) with $\rho(L ; \theta)=\left(1-L^{2}\right)^{d+\theta}$ and white noise $\mathrm{u}_{\mathrm{t}}$ for the Japanese data

\begin{tabular}{|c|c|c|c|c|c|c|c|c|c|}
\hline Series & $\mathrm{z}_{\mathrm{t}} / \mathrm{d}$ & 0.50 & 0.75 & 1.00 & 1.25 & 1.50 & 1.75 & 2.00 & 2.25 \\
\hline \multirow{5}{*}{$\mathrm{c}_{\mathrm{t}}$} & -- & 4.42 & $1.7 \gamma^{\prime}$ & -0.47 & $-1.91^{\prime}$ & -2.75 & -3.25 & -3.58 & -3.80 \\
\cline { 2 - 10 } & $\mathrm{I}$ & 2.75 & -4.04 & -4.61 & -4.75 & -4.84 & -4.88 & -4.91 & -4.92 \\
\cline { 2 - 10 } & $\mathrm{I}, \mathrm{T}$ & -0.96 & -3.71 & -4.58 & -4.82 & -4.89 & -4.92 & -4.94 & -4.95 \\
\cline { 2 - 10 } & $\mathrm{I}, \mathrm{S}$ & 6.87 & 3.85 & 1.94 & -0.84 & -2.80 & -3.73 & -4.14 & -4.34 \\
\cline { 2 - 10 } & $\mathrm{I}, \mathrm{T}, \mathrm{S}$ & 12.14 & 7.99 & 2.04 & -1.93 & -3.49 & -3.99 & -4.21 & -4.35 \\
\hline \hline \multirow{5}{*}{$\mathrm{y}_{\mathrm{t}}$} & -- & 4.13 & 1.55 & -0.66 & -2.06 & -2.87 & -3.35 & -3.67 & -3.89 \\
\cline { 2 - 10 } & $\mathrm{I}$ & -1.23 & -4.72 & -4.83 & -4.87 & -4.90 & -4.92 & -4.93 & -4.94 \\
\cline { 2 - 10 } & $\mathrm{I}, \mathrm{T}$ & -3.38 & -4.51 & -4.81 & -4.89 & -4.92 & -4.94 & -4.95 & -4.96 \\
\cline { 2 - 10 } & $\mathrm{I}, \mathrm{S}$ & 6.57 & 0.44 & -2.84 & -4.05 & -4.55 & -4.73 & -4.79 & -4.81 \\
\cline { 2 - 10 } & $\mathrm{I}, \mathrm{T}, \mathrm{S}$ & 7.78 & 1.25 & -2.86 & -4.28 & -4.66 & -4.72 & -4.72 & -4.74 \\
\hline \hline \multirow{5}{*}{$\mathrm{c}_{\mathrm{t}}-\mathrm{y}_{\mathrm{t}}$} & -- & -4.25 & -4.63 & -4.80 & -4.87 & -4.91 & -4.93 & -4.94 & -4.95 \\
\cline { 2 - 10 } & $\mathrm{I}$ & -4.55 & -4.81 & -4.87 & -4.89 & -4.91 & -4.92 & -4.92 & -4.93 \\
\cline { 2 - 10 } & $\mathrm{I}, \mathrm{T}$ & -4.51 & -4.79 & -4.86 & -4.89 & -4.91 & -4.92 & -4.93 & -4.94 \\
\cline { 2 - 10 } & $\mathrm{I}, \mathrm{S}$ & -1.11 & -3.40 & -4.20 & -4.50 & -4.63 & -4.69 & -4.73 & -4.76 \\
\cline { 2 - 10 } & $\mathrm{I}, \mathrm{T}, \mathrm{S}$ & -1.14 & -3.39 & -4.20 & -4.50 & -4.62 & -4.66 & -4.67 & -4.69 \\
\hline
\end{tabular}

$\because$ : Non-rejection values for the null hypothesis (11) at 95\% significance level. --: No intercept, no time trend and no seasonal dummies; I: An intercept; I,T: An intercept and a time trend; I,S: An intercept and seasonal dummies; I,S,T: An intercept, a time trend and seasonal dummies.

\section{TABLE 10}

$\hat{r}$ in $(12)$ with $\rho(L ; \theta)=(1-L)^{d+\theta}$ and white noise $\mathrm{u}_{\mathrm{t}}$ for the Japanese data

\begin{tabular}{|c|c|c|c|c|c|c|c|c|c|}
\hline Series & $\mathrm{z}_{\mathrm{t}} / \mathrm{d}$ & 0.50 & 0.75 & 1.00 & 1.25 & 1.50 & 1.75 & 2.00 & 2.25 \\
\hline \multirow{5}{*}{$\mathrm{c}_{\mathrm{t}}$} & -- & 8.47 & 3.43 & -0.37 & -2.49 & -3.61 & -4.27 & -4.70 & -4.99 \\
\cline { 2 - 10 } & $\mathrm{I}$ & 3.17 & -4.31 & -4.61 & -4.83 & -5.02 & -5.18 & -5.33 & -5.46 \\
\cline { 2 - 10 } & $\mathrm{I}, \mathrm{T}$ & -1.51 & -3.93 & -4.59 & -4.85 & -5.04 & -5.19 & -5.33 & -5.46 \\
\cline { 2 - 10 } & $\mathrm{I}, \mathrm{S}$ & 12.74 & 3.01 & -2.47 & -4.54 & -5.37 & -5.68 & -5.83 & -5.93 \\
\cline { 2 - 10 } & $\mathrm{I}, \mathrm{T}, \mathrm{S}$ & 16.98 & 5.30 & -2.52 & -4.86 & -5.47 & -5.69 & -5.82 & -5.91 \\
\hline \hline \multirow{5}{*}{$\mathrm{y}_{\mathrm{t}}$} & -- & 7.35 & 2.47 & -1.07 & -2.98 & -3.98 & -4.57 & -4.95 & -5.21 \\
\cline { 2 - 10 } & $\mathrm{I}$ & -2.71 & -4.98 & -5.11 & -5.27 & -5.42 & -5.55 & -5.67 & -5.78 \\
\cline { 2 - 10 } & $\mathrm{I}, \mathrm{T}$ & -4.03 & -4.82 & -5.10 & -5.28 & -5.43 & -5.56 & -5.68 & -5.78 \\
\cline { 2 - 10 } & $\mathrm{I}, \mathrm{S}$ & 11.76 & -0.13 & -3.38 & -4.26 & -4.62 & -4.81 & -4.96 & -5.08 \\
\cline { 2 - 10 } & $\mathrm{I}, \mathrm{T}, \mathrm{S}$ & 10.31 & 0.31 & -3.42 & -4.35 & -4.64 & -4.79 & -4.90 & -5.00 \\
\hline \hline \multirow{5}{*}{$\mathrm{c}_{\mathrm{t}}-\mathrm{y}_{\mathrm{t}}$} & -- & -4.74 & -5.09 & -5.31 & -5.47 & -5.60 & -5.72 & -5.82 & -5.91 \\
\cline { 2 - 10 } & $\mathrm{I}$ & -4.95 & -5.16 & -5.32 & -5.47 & -5.60 & -5.71 & -5.82 & -5.91 \\
\cline { 2 - 10 } & $\mathrm{I}, \mathrm{T}$ & -4.89 & -5.14 & -5.32 & -5.47 & -5.60 & -5.72 & -5.83 & -5.91 \\
\cline { 2 - 10 } & $\mathrm{I}, \mathrm{S}$ & -2.88 & -4.56 & -5.10 & -5.35 & -5.51 & -5.63 & -5.74 & -5.82 \\
\cline { 2 - 9 } & $\mathrm{I}, \mathrm{T}, \mathrm{S}$ & -2.91 & -4.56 & -5.10 & -5.35 & -5.50 & -5.60 & -5.67 & -5.73 \\
\hline
\end{tabular}

': Non-rejection values for the null hypothesis (11) at 95\% significance level. --: No intercept, no time trend and no seasonal dummies; I: An intercept; I,T: An intercept and a time trend; I,S: An intercept and seasonal dummies; I,S,T: An intercept, a time trend and seasonal dummie 